\title{
Comparison of the inversion algorithms applied to the ozone vertical profile retrieval from SCIAMACHY limb measurements
}

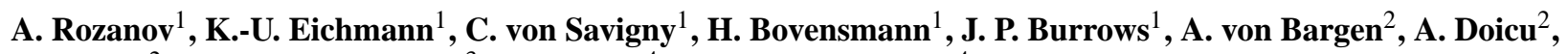 \\ S. Hilgers ${ }^{2}$, S. Godin-Beekmann ${ }^{3}$, T. Leblanc ${ }^{4}$, and I. S. McDermid ${ }^{4}$ \\ ${ }^{1}$ Institute of Environmental Physics (IUP), University of Bremen, Bremen, Germany \\ ${ }^{2}$ German Aerospace Center (DLR) Oberpfaffenhofen, Oberpfaffenhofen, Germany \\ ${ }^{3}$ Service d'Aéronomie - CNRS, Institut Pierre Simon Laplace, Paris, France \\ ${ }^{4}$ Jet Propulsion Laboratory, Table Mountain Facility, Wrightwood, CA 92397-0367, USA
}

Received: 18 December 2006 - Published in Atmos. Chem. Phys. Discuss.: 7 February 2007

Revised: 20 June 2007 - Accepted: 13 September 2007 - Published: 20 September 2007

\begin{abstract}
This paper is devoted to an intercomparison of ozone vertical profiles retrieved from the measurements of scattered solar radiation performed by the SCIAMACHY instrument in the limb viewing geometry. Three different inversion algorithms including the prototype of the operational Level 1 to 2 processor to be operated by the European Space Agency are considered. Unlike usual validation studies, this comparison removes the uncertainties arising when comparing measurements made by different instruments probing slightly different air masses and focuses on the uncertainties specific to the modeling-retrieval problem only. The intercomparison was performed for 5 selected orbits of SCIAMACHY showing a good overall agreement of the results in the middle stratosphere, whereas considerable discrepancies were identified in the lower stratosphere and upper troposphere altitude region. Additionally, comparisons with ground-based lidar measurements are shown for selected profiles demonstrating an overall correctness of the retrievals.
\end{abstract}

\section{Introduction}

The Scanning Imaging Absorption spectroMeter for Atmospheric CHartographY (SCIAMACHY) (Bovensmann et al., 1999) launched on board the European Environment Satellite (ENVISAT-1) in March 2002 is one of the new-generation space-borne instruments capable of performing spectrally resolved limb measurements of the solar radiation scattered in the Earth's atmosphere. This novel remote sensing technique allows daily near-global measurements of the atmospheric composition from space with a vertical resolution

Correspondence to: A. Rozanov

(alexei.rozanov@iup.physik.uni-bremen.de) of 2-3 km (McPeters et al., 2000; von Savigny et al., 2003, 2005b; Rozanov et al., 2005a).

Retrievals of limb measurements performed by spaceborne instruments launched previously as well as first retrievals of SCIAMACHY measurements demonstrate a huge information content of scattered solar light observations performed in the limb viewing geometry. However, due to the complexity of the scattering processes which the solar light detected by limb-viewing space-borne instruments undergoes, the retrieval of atmospheric trace gases from limb measurements requires sophisticated forward modeling and inversion approaches. The SCIAMACHY instrument achieves a full global coverage in 6 days which results in a large amount of measured data requiring the operational retrieval algorithms to be numerically efficient.

In this paper three different algorithms aimed at retrieving the vertical distribution of ozone from SCIAMACHY limb measurements are considered. The first one, based on the global fit method, was developed at the German Aerospace Center (DLR) Oberpfaffenhofen on behalf of the European Space Agency to be used as a part of the operational Level 1 to 2 data processing software. In the current study version 3.0 of the DLR retrieval processor was employed. The second algorithm based on the so-called triplet method was developed at the Institute of Environmental Physics of the University of Bremen to perform the routine retrieval of the ozone vertical profiles (von Savigny et al., 2005b). This method will be further referenced to as the Stratozone algorithm. Throughout this study version 1.62 of the Stratozone retrieval algorithm was employed. An extended database of vertical distributions of ozone retrieved for all available limb measurements performed since September 2002 until now using the Stratozone algorithm is available through the web site of the Institute of Environmental Physics ${ }^{1}$. The third algorithm also

\footnotetext{
${ }^{1}$ http://www.iup.physik.uni-bremen.de/scia-arc/
} 
based on the global fit method is a part of the SCIATRAN 2.1 software package (Rozanov, 2004-2007; Rozanov et al., 2005a,b) comprising the radiative transfer model and the retrieval module, which was developed at the Institute of Environmental Physics of the University of Bremen as well. A detailed description of the retrieval processors will be presented in Sect. 3.

Recently, several papers were published dealing with the validation of ozone vertical profiles retrieved from SCIAMACHY limb measurements. In particular, Segers et al. (2005) and Brinksma et al. (2006) have presented validation results for precursor versions of the retrieval algorithms discussed in this study, namely, versions 2.4 and 2.5 of the DLR retrieval processor as well as versions 1.6 and 1.61 of the Stratozone algorithm. Although, such validation activities are extremely important to estimate the overall quality of the measurement-modeling-retrieval complex they can not answer the question which part of the disagreement originates from the modeling and retrieval errors and which is caused by systematic errors in the measurements, different measurement methodologies of the intercompared instruments, uncertainties due to different air masses seen by different types of measurements and so on. Contrary to previous studies, this paper contains only a few comparisons with independent instruments and focuses on the deviations in retrieved ozone profiles when applying different retrieval processors to the same measurement data set. The main goal of this study is to highlight the uncertainties related to the forward modeling and to the response of different retrieval techniques to SCIAMACHY specific systematic errors, rejecting from the consideration major uncertainties resulted from, for example, SCIAMACHY mispointing, probing different air masses, and so on.

The version 1.62 of the Stratozone retrieval processor considered in this study does not differ much from the previous versions 1.6 and 1.61 extensively validated by Segers et al. (2005) and Brinksma et al. (2006), respectively. Both versions 1.6 and 1.61 were based on SCIAMACHY Level 0 data with only a dark current correction applied, whereas version 1.62 uses the calibrated Level 1 dataset as described below. Furthermore, contrary to version 1.62 where the retrievals are performed on a $1 \mathrm{~km}$ altitude grid, version 1.61 used the tangent height grid of every single limb measurement as the retrieval altitude grid whereas in version 1.6 a fixed equidistant grid of $3.3 \mathrm{~km}$ spacing was utilized. According to the validation results of versions 1.6 and 1.61, the pointing corrected Stratozone retrievals are expected to agree with independent measurements within $10-20 \%$ between 20 and $40 \mathrm{~km}$. The validation results for versions 2.4 and 2.5 of the DLR retrieval processor as presented by Brinksma et al. (2006) are no longer relevant since the retrieval approach used by the DLR group has recently undergone major changes. Thus, version 3.0 of the DLR retrieval processor has almost nothing in common with the precursor versions and can be considered as a newly developed algorithm. Among others, the spectral region was changed from around $320 \mathrm{~nm}$ to 520 $580 \mathrm{~nm}$, differential signal instead of normalized radiances is used, the retrieval approach was changed from the standard optimal estimation to the iteratively regularized GaussNewton method, and a constant regularization parameter was replaced by the L-Curve method to select the optimal value.

\section{SCIAMACHY limb observations}

The SCIAMACHY instrument is a passive imaging spectrometer comprising 8 spectral channels covering a wide spectral range from 240 to $2400 \mathrm{~nm}$. Each spectral channel is equipped with a grating spectrometer having an 1024 element diode array as a detector. For the current study only the measurements in spectral channels 3 and 4 ranging from 394 to $620 \mathrm{~nm}$ and from 604 to $805 \mathrm{~nm}$, respectively, were used. Channels 3 and 4 of the SCIAMACHY instrument are characterized by the spectral resolution of 0.44 and $0.48 \mathrm{~nm}$, respectively, and the spectral sampling of 0.22 and $0.24 \mathrm{~nm}$, respectively.

In the limb viewing geometry the SCIAMACHY instrument observes the atmosphere tangentially to the Earth's surface starting at about $3 \mathrm{~km}$ below the horizon, i.e., when the Earth's surface is still within the field of view of the instrument, and then scanning vertically up to the top of the atmosphere (about $100 \mathrm{~km}$ tangent height). At each tangent height a horizontal scan of the duration of $1.5 \mathrm{~s}$ is performed followed by an elevation step of about $3.3 \mathrm{~km}$. No measurements are performed during the vertical repositioning. Thus, the limb observation sequence is performed with a vertical sampling of $3.3 \mathrm{~km}$. In the altitude range relevant for this study, most typical tangent heights of the limb measurements are located around $13.4 \mathrm{~km}, 16.7 \mathrm{~km}, 19.9 \mathrm{~km}$, $23.2 \mathrm{~km}, 26.5 \mathrm{~km}, 29.7 \mathrm{~km}, 33.0 \mathrm{~km}, 36.3 \mathrm{~km}, 39.6 \mathrm{~km}$, $42.9 \mathrm{~km}, 46.2 \mathrm{~km}$, and $49.4 \mathrm{~km}$. The vertical instantaneous field of view of the SCIAMACHY instrument is about $2.5 \mathrm{~km}$ at the tangent point. Although the horizontal instantaneous field of view of the instrument is about $110 \mathrm{~km}$ at the tangent point, the cross-track horizontal resolution is mainly determined by the integration time during the azimuthal (i.e., horizontal cross-track) scan reaching typically about $240 \mathrm{~km}$. However, in this study all spectra measured during the azimuthal scans were averaged to increase the quality of the input data, which results in a cross-track resolution of about $960 \mathrm{~km}$.

In most of the spectral intervals considered in this study, typical values of the signal to noise ratio in horizontally integrated limb measurements range from 3000 to 10000 at tangent heights between 20 and $30 \mathrm{~km}$ decreasing to about 1000 near the normalization tangent height altitude $(\approx 50 \mathrm{~km})$. However, towards the long wavelength boundary of the channel $3(\lambda>590 \mathrm{~nm})$ the signal to noise ratio rapidly decreases down to 500-1500 at tangent heights between 20 and $30 \mathrm{~km}$ and 100-200 near the normalization tangent height altitude. 
Further details on signal to noise characteristics of the SCIAMACHY instrument can be found in (Noël et al., 1998).

Throughout this study, SCIAMACHY Level 1 data were used with the calibration steps from 0 to 5 applied, i.e, the wavelength calibration was performed and the corrections for memory effect, leakage current, pixel-to-pixel gain, etalon, and internal straylight were accounted for, whereas the polarization correction as well as the absolute radiometric calibration were skipped.

\section{Retrieval processors}

The inverse problem related to the interpretation of spaceborne observations of the scattered solar light performed in the limb viewing geometry is to retrieve vertical distributions of various atmospheric parameters from spectroscopic measurements. From a computational point of view the basic problem is the inversion of the radiative transfer equation which provides a relation between the atmospheric parameters and the intensity of the radiation as observed by the instrument. In a discrete representation the data model is written as follows:

$\boldsymbol{y}=\mathbf{F}(\boldsymbol{x})$

where the mapping $\mathbf{F}$ represents the radiative transfer operator, also referenced as the forward model operator, $\boldsymbol{y}$ is the exact data vector, and $\boldsymbol{x}$ is the state vector containing the atmospheric parameters (e.g., molecular density profiles, aerosol characteristics, etc.) to be retrieved. Since measurements are performed to a finite accuracy, only the noisy data vector,

$\boldsymbol{y}_{\varepsilon}=\boldsymbol{y}+\varepsilon$,

is available in practice. The measurement error $\varepsilon$ has to be assumed to be stochastic, normally distributed, and have zero mean to meet the applicability requirements of the statistical inversion methods, e.g., the optimal estimation technique (Rodgers, 2000), used in this study. Furthermore, the standard inversion methods are developed for linear problems which is not the case for the data model represented by Eq. (1). To linearize this equation, the Taylor series expansion around an initial guess, $\boldsymbol{x}_{\mathrm{a}}$, is applied:

$\boldsymbol{y}=\mathbf{F}\left(\boldsymbol{x}_{\mathrm{a}}\right)+\left.\frac{\delta \mathbf{F}(\boldsymbol{x})}{\delta \boldsymbol{x}}\right|_{\boldsymbol{x}=\boldsymbol{x}_{\mathrm{a}}} \times\left(\boldsymbol{x}-\boldsymbol{x}_{\mathrm{a}}\right)+\ldots$

Here, the initial guess, $\boldsymbol{x}_{\mathrm{a}}$, also referenced as the a priori state vector, is the best beforehand estimator of the true solution. Neglecting the higher order terms in the Taylor series expansion a linear relation between the atmospheric parameters and the intensity of the radiation is obtained:

$$
\begin{array}{r}
\boldsymbol{y}=\mathbf{F}\left(\boldsymbol{x}_{\mathrm{a}}\right)+\left.\frac{\delta \mathbf{F}(\boldsymbol{x})}{\delta \boldsymbol{x}}\right|_{\boldsymbol{x}=\boldsymbol{x}_{\mathrm{a}}} \times\left(\boldsymbol{x}-\boldsymbol{x}_{\mathrm{a}}\right)+\epsilon \approx \\
\mathbf{F}\left(\boldsymbol{x}_{\mathrm{a}}\right)+\mathbf{K}\left(\boldsymbol{x}-\boldsymbol{x}_{\mathrm{a}}\right),
\end{array}
$$

where $\epsilon$ is the linearization error and $\left.\mathbf{K} \equiv \frac{\delta \mathbf{F}(\boldsymbol{x})}{\delta \boldsymbol{x}}\right|_{\boldsymbol{x}=\boldsymbol{x}_{\mathrm{a}}}$ is the variational derivative matrix also referenced as the weighting function matrix. The resulting linear inverse ill-posed problem, as represented by Eq. (4), is solved in the least squares sense by means of Tikhonov regularization with a stochastic constraint. This stochastic version of Tikhonov regularization is equivalent to the optimal estimation method described by Rodgers (2000). Essentially, an approximate solution is computed minimizing the following quadratic form:

$$
\begin{aligned}
\mathcal{F}(\boldsymbol{x})=\left\|\mathbf{F}\left(\boldsymbol{x}_{\mathrm{a}}\right)+\mathbf{K}\left(\boldsymbol{x}-\boldsymbol{x}_{\mathrm{a}}\right)-\boldsymbol{y}_{\varepsilon}\right\|_{\mathbf{S}_{\varepsilon}^{-1}}^{2}+ & \left\|\left(\boldsymbol{x}-\boldsymbol{x}_{\mathrm{a}}\right)\right\|_{\mathbf{S}_{\mathrm{a}}^{-1}}^{2},
\end{aligned}
$$

where $\mathbf{S}_{\varepsilon}$ is the noise covariance and $\mathbf{S}_{a}$ is the a priori covariance matrices. A specific approach to form the data model as well as to solve the minimization problem as given by Eq. (5) varies for different implementations and, therefore, will be discussed below for each retrieval processor separately.

\subsection{Stratozone retrieval processor}

The Stratozone retrieval processor developed at the Institute of Environmental Physics of the University of Bremen exploits the differential absorption structure between the center and the wings of the Chappuis absorption band of ozone, centered at $600 \mathrm{~nm}$ (von Savigny et al., 2005b). The retrieval algorithm is based on the so-called triplet method developed by Flittner et al. (2000) that was originally used to retrieve stratospheric ozone profiles from limb scattered radiances measured by the SOLSE/LORE (Shuttle Ozone Limb Sounding Experiment/Limb Ozone Retrieval Experiment) instrumentation (McPeters et al., 2000). A similar technique is also used to retrieve stratospheric ozone profiles from limb scatter measurements performed by the OSIRIS (Optical Spectrograph and InfraRed Imager System) instrument on board the Swedish satellite Odin (von Savigny et al., 2003).

The main idea of the triplet method is to combine the limb radiance profiles (i.e., observed limb radiances, $I(\lambda, h)$, as functions of the tangent height, $h$ ) averaged over $2 \mathrm{~nm}$ spectral intervals centered around $\lambda_{1}=525 \mathrm{~nm}, \lambda_{2}=600$, and $\lambda_{3}=675 \mathrm{~nm}$ into the so-called Chappuis vector as follows:

$\{\boldsymbol{J}\}_{\mathrm{k}}=\ln \left[\frac{I\left(\lambda_{2}, h_{\mathrm{k}}\right)}{\sqrt{I\left(\lambda_{1}, h_{\mathrm{k}}\right) I\left(\lambda_{3}, h_{\mathrm{k}}\right)}}\right], \mathrm{k}=1, \ldots, \mathrm{N}_{\mathrm{k}}$,

where the notation $\{\boldsymbol{J}\}_{\mathrm{k}}$ denotes the $\mathrm{k}$-th component of the vector $\boldsymbol{J}$ and $\mathrm{N}_{\mathrm{k}}$ is the total number of the tangent heights included in the retrieval. The state vector, $\boldsymbol{x}$, contains ozone concentrations at discrete altitude levels:

$\{\boldsymbol{x}\}_{j}=n_{\mathrm{O}_{3}}\left(\mathrm{H}_{j}\right), \quad j=1, \ldots, \mathrm{N}_{j}$,

where $\mathrm{N}_{j}$ is the total number of discrete altitude levels in the forward model, i.e., the j-th component of the state vector, $\boldsymbol{x}$, contains the ozone concentration at the altitude level $\mathrm{H}_{j}$. 
To reduce the influence of instrument calibration effects as well as of broadband spectral features, for example, due to aerosol scattering or spectral dependent surface albedo, the normalized Chappuis vector is used in the data model:

$$
\begin{aligned}
& \left\{\boldsymbol{y}_{\varepsilon}\right\}_{\mathrm{k}}=\left\{\boldsymbol{J}^{\text {meas }}\right\}_{\mathrm{k}}-J_{\mathrm{ref}}^{\text {meas }}, \mathrm{k}=1, \ldots, \mathrm{N}_{\mathrm{k}}, \\
& \left\{\mathbf{F}\left(\boldsymbol{x}_{\mathrm{a}}\right)\right\}_{\mathrm{k}}=\left\{\boldsymbol{J}^{\mathrm{sim}}\right\}_{\mathrm{k}}-J_{\mathrm{ref}}^{\text {sim }}, \\
& \{\mathbf{K}\}_{\mathrm{k}, j}=\left.\frac{\delta\{\mathbf{F}(\boldsymbol{x})\}_{\mathrm{k}}}{\delta\{\boldsymbol{x}\}_{j}}\right|_{\boldsymbol{x}=\boldsymbol{x}_{\mathrm{a}}}, j=1, \ldots, \mathrm{N}_{j} .
\end{aligned}
$$

Here, the normalization is done with respect to the limb radiance at an upper tangent height which is commonly referred to as the reference tangent height, $h_{\mathrm{ref}}$ :

$$
J_{\text {ref }}=\ln \left[\frac{I\left(\lambda_{2}, h_{\text {ref }}\right)}{\sqrt{I\left(\lambda_{1}, h_{\text {ref }}\right) I\left(\lambda_{3}, h_{\text {ref }}\right)}}\right] .
$$

The synthetic Chappuis vector as well as the corresponding weighting functions are calculated using the SCIARAYS radiative transfer model (Kaiser and Burrows, 2003) taking into account the refractive ray tracing. The limb radiance is simulated considering two orders of scattering and the surface reflection whereas the weighting functions are calculated in the single scattering approximation which was found to be sufficient for the ozone vertical profile retrieval from limb measurements in UV - Visible spectral range.

The minimization problem as given by Eq. (5) is solved employing the conventional optimal estimation method and the non-linearity of the problem is accounted for using the Gauss-Newton iterative approach. Thus, the solution at $(i+1)$-th iteration is given by:

$$
\begin{aligned}
\boldsymbol{x}_{\mathrm{i}+1}=\boldsymbol{x}_{\mathrm{a}}+ & \left(\mathbf{K}_{\mathrm{i}}^{T} \mathbf{S}_{\varepsilon}^{-1} \mathbf{K}_{\mathrm{i}}+\mathbf{S}_{\mathrm{a}}^{-1}\right)^{-1} \times \\
& \mathbf{K}_{\mathrm{i}}^{T} \mathbf{S}_{\varepsilon}^{-1}\left(\boldsymbol{y}_{\varepsilon}-\mathbf{F}\left(\boldsymbol{x}_{\dot{1}}\right)+\mathbf{K}_{\mathrm{i}}\left(\boldsymbol{x}_{\mathrm{i}}-\boldsymbol{x}_{\mathrm{a}}\right)\right) .
\end{aligned}
$$

The iterative process is stopped if the maximum difference between the components of the solution vector at two subsequent iterative steps does not exceed $1 \%$. Typically $3-5$ iterations are required to achieve the convergence.

\subsection{SCIATRAN retrieval processor}

SCIATRAN is a scientific retrieval processor based on the SCIATRAN 2.1 retrieval package (Rozanov, 2004-2007), which was developed at the Institute of Environmental Physics of the University of Bremen to retrieve the vertical distributions of atmospheric trace gases from SCIAMACHY limb measurements using the differential absorption structure. The algorithm employed in this study exploits the differential spectra in the short wavelength wing of the Chappuis absorption band of ozone and the global fit approach. A similar technique was also used to retrieve the vertical distributions of $\mathrm{NO}_{2}$ and $\mathrm{BrO}$ from SCIAMACHY limb measurements (Rozanov et al., 2005a).
Similar to the Stratozone retrieval processor, the first $\mathrm{N}_{j}$ components of the state vector, $\boldsymbol{x}$, contain ozone concentrations at the altitude grid corresponding to the forward model discretization levels. However, since the scaling factors for $\mathrm{NO}_{2}$ and $\mathrm{O}_{4}$ vertical profiles are also fitted, the state vector contains two additional components, namely, vertical columns of $\mathrm{NO}_{2}$ and $\mathrm{O}_{4}$, i.e.,

$$
\begin{aligned}
& \{\boldsymbol{x}\}_{j}=n_{\mathrm{O}_{3}}\left(\mathrm{H}_{j}\right), \quad j=1, \ldots, \mathrm{N}_{j}, \\
& \{\boldsymbol{x}\}_{\mathrm{N}_{j}+1}=v_{\mathrm{NO}_{2}}, \quad\{\boldsymbol{x}\}_{\mathrm{N}_{j}+2}=v_{\mathrm{O}_{4}} .
\end{aligned}
$$

The data model comprises the spectral information in all spectral points obtained at all tangent heights in the selected range and relies on the DOAS (Differential Optical Absorption Spectroscopy) technique (Platt, 1994). Similar to the Stratozone method the limb radiances are normalized with respect to the limb spectrum measured at an upper tangent height in order to eliminate the solar Fraunhofer structure and to minimize the influence of the instrument response function, i.e., the need for an absolute instrument calibration. Thus, the data model is expressed as follows:

$$
\begin{aligned}
& \left\{\boldsymbol{y}_{\varepsilon}\right\}_{\mathrm{N}_{\mathrm{L}}(\mathrm{k}-1)+\mathrm{L}}=\ln \left[\frac{I^{\text {meas }}\left(\lambda_{\mathrm{L}}, h_{\mathrm{k}}\right)}{I^{\text {meas }}\left(\lambda_{\mathrm{L}}, h_{\mathrm{ref}}\right)}\right]-P_{n}^{\text {meas }}, \\
& \left\{\mathbf{F}\left(\boldsymbol{x}_{\mathrm{a}}\right)\right\}_{\mathrm{N}_{\mathrm{L}}(\mathrm{k}-1)+\mathrm{L}}=\ln \left[\frac{I^{\mathrm{sim}}\left(\lambda_{\mathrm{L}}, h_{\mathrm{k}}\right)}{I^{\operatorname{sim}}\left(\lambda_{\mathrm{L}}, h_{\mathrm{ref}}\right)}\right]-P_{n}^{\text {sim }}, \\
& \{\mathbf{K}\}_{\mathrm{N}_{\mathrm{L}}(\mathrm{k}-1)+\mathrm{L}, j}=\left.\frac{\delta\{\mathbf{F}(\boldsymbol{x})\}_{\mathrm{N}_{\mathrm{L}}(\mathrm{k}-1)+\mathrm{L}}}{\delta\{\boldsymbol{x}\}_{\mathrm{j}}}\right|_{\boldsymbol{x}=\boldsymbol{x}_{\mathrm{a}}}-P_{n}^{\mathrm{wf}}, \\
& \mathrm{L}=1, \ldots, \mathrm{N}_{\mathrm{L}}, \quad \mathrm{k}=1, \ldots, \mathrm{N}_{\mathrm{k}}, \quad j=1, \ldots, \mathrm{N}_{j},
\end{aligned}
$$

where $P_{n}$ is a polynomial of order $n$ in $\lambda$, whose coefficients are obtained by fitting the logarithms of the normalized limb radiance in the wavelength domain for each tangent height independently. By subtracting low-order polynomials from the radiance spectra we remove those spectral features that are smoothly varying functions of wavelength, particularly those due to Rayleigh and Mie scattering. In the current study a cubic polynomial was subtracted.

The synthetic limb radiance spectra as well as appropriate weighting functions are calculated with the SCIATRAN radiative transfer model (Rozanov et al., 2005b) taking into account the refractive ray tracing. The limb radiance is simulated in the approximative multiple scattering mode employing the combined differential-integral approach whereas the weighting functions are calculated similar to the Stratozone retrieval processor in the single scattering approximation. In the framework of the combined differential-integral approach the single scattering contribution is treated fully spherically and an approximation for the multiply scattered light is obtained integrating along the line of sight the multiple scattering contributions calculated using a pseudo-spherical model for a proper atmospheric location and illumination. A detailed description of the employed approach can be found in (Rozanov et al., 2001).

The minimization problem is solved employing the information operator approach (Kozlov, 1983; Hoogen et al., 
1999; Rozanov, 2001). The main idea of the method is to project the solution into the space of eigenvectors of the information operator defined by

$\mathbf{P}=\mathbf{S}_{\mathrm{a}} \mathbf{K}^{T} \mathbf{S}_{\varepsilon}^{-1} \mathbf{K}$.

The effective state subspace accessible with the measurement is defined considering only the eigenvectors whose eigenvalues are larger than 1 . The non-linearity of the inverse problem is accounted for employing the Levenberg-Marquardt iterative method where, unlike the Gauss-Newton iterative scheme as used in the Stratozone retrieval processor, the a priori state vector is replaced by the state vector obtained at the previous iterative step. In this case, the solution at $(i+1)$-th iterative step is written as follows:

$\boldsymbol{x}_{\mathrm{i}+1}=\boldsymbol{x}_{\mathrm{i}}+\sum_{\mathrm{k}=1}^{\mathrm{N}_{\mathrm{i}}} \beta_{\mathrm{i}, \mathrm{k}} \boldsymbol{\psi}_{\mathrm{i}, \mathrm{k}}$,

where $\psi_{i, k}$ are the eigenvectors of the information operator, $\mathbf{P}$, the number of significant eigenvectors, i.e., eigenvectors whose eigenvalues are larger than 1 , is represented by $\mathrm{N}_{i}$, and the expansion coefficients $\beta_{i, \mathrm{k}}$ are given by

$\beta_{i, \mathrm{k}}=\frac{\eta_{i, \mathrm{k}}}{\mathrm{C}_{\mathrm{i}, \mathrm{k}}\left(1+\eta_{\mathrm{i}, \mathrm{k}}\right)} \boldsymbol{\psi}_{\mathrm{i}, \mathrm{k}}^{T} \mathbf{K}_{\mathrm{i}}^{T} \mathbf{S}_{\varepsilon}^{-1}\left(\boldsymbol{y}_{\varepsilon}-\mathbf{F}\left(\boldsymbol{x}_{\mathrm{i}}\right)\right)$.

Here, $\eta_{i, k}$ denotes the eigenvalue of the information operator, $\mathbf{P}$, corresponding to the eigenvector $\boldsymbol{\psi}_{\mathrm{i}, \mathrm{k}}$ and $c_{\mathrm{i}, \mathrm{k}}$ is the following scalar product:

$\mathrm{C}_{\mathrm{i}, \mathrm{k}}=\left\langle\mathbf{K}_{\mathrm{i}}^{T} \mathbf{S}_{\varepsilon}^{-1} \mathbf{K}_{\mathrm{i}} \boldsymbol{\psi}_{\mathrm{i}, \mathrm{k}} \mid \boldsymbol{\psi}_{\mathrm{i}, \mathrm{k}}\right\rangle$.

At the beginning of the iterative process the standard deviations for relative changes of the retrieval parameters (i.e., percentage values) are specified. These relative standard deviations remain unchanged during the iterative process. However, at each iterative step they are multiplied by the state vector obtained at the previous iteration when calculating the corresponding a priori covariance matrix $\mathbf{S}_{a}$, which describes the absolute variations of the retrieved parameters. The iterative process is stopped if the maximum difference between the components of the solution vector at two subsequent iterative steps does not exceed $1 \%$. Typically 5-7 iterations are required to achieve the convergence.

The described truncated projection method results in an additional noise filtering during the retrieval process and, thus, more stable solution is obtained. However, if the selected regularization parameters are too strong, some eigenvectors still containing useful information on the vertical distribution of the retrieved atmospheric parameters can be treated as noise and rejected from the projection space, which may result in a partial loss of the vertical resolution leading to oversmoothed profiles. Furthermore, the LevenbergMarquardt iterative method applied in the SCIATRAN retrieval processor makes it much less dependent on the a priori information as compared to other retrievals increasing, however, its sensitivity to systematic errors.

\subsection{DLR retrieval processor}

The DLR retrieval processor is a prototype of the operational Level 1 to 2 SCIAMACHY limb data processor developed at the German Aerospace Center (DLR) Oberpfaffenhofen on behalf of the European Space Agency. Similar to SCIATRAN, the DLR retrieval processor exploits the differential spectral structure in the short wavelength wing of the Chappuis absorption band and the global fit approach to retrieve the vertical distribution of ozone.

Although, the state vector in the DLR retrieval processor is formed in the similar way as in SCIATRAN, see Eqs. (13) and (14), the first $\mathrm{N}_{j}$ elements of this vector contain the partial columns of ozone within the altitude layers (i.e., between the altitude grid levels) rather than the concentrations at grid levels as in SCIATRAN, whereas the last two components remain the same:

$$
\begin{aligned}
& \{\boldsymbol{x}\}_{j}=\frac{\Delta \mathrm{H}_{j}}{2}\left[n_{\mathrm{O}_{3}}\left(\mathrm{H}_{j+1}\right)+n_{\mathrm{O}_{3}}\left(\mathrm{H}_{j}\right)\right], j=1, \ldots, \mathrm{N}_{j}, \\
& \{\boldsymbol{x}\}_{\mathrm{N}_{j}+1}=v_{\mathrm{NO}_{2}},\{\boldsymbol{x}\}_{\mathrm{N}_{j}+2}=v_{\mathrm{O}_{4}},
\end{aligned}
$$

where $\Delta H_{j}=\left|H_{j+1}-H_{j}\right|$ is the geometrical thickness of the altitude layer. The data model uses the normalized differential spectral information in the entire spectral range selected for the retrieval obtained at all tangent heights of interest in exactly the same manner as implemented in the SCIATRAN retrieval processor, see Eqs. (15)-(17). The normalization is also done with respect to a limb measurement at an upper tangent height and a cubic polynomial was used throughout this study to highlight the differential absorption structure.

The radiative transfer model incorporated into the DLR retrieval package employs the LIDORT algorithm (Spurr et al., 2001) to calculate the single scattered radiation taking into account the refractive ray tracing and look-up tables to approximate the contribution due to the multiple scattering. The look-up tables contain the multiple scattering corrections as functions of wavelength and observation geometry generated using the SCIATRAN radiative transfer model (Rozanov et al., 2005b) for a set of solar zenith angles, surface albedos, atmospheric models (i.e., pressure, temperature, and ozone profiles), as well as aerosol loading scenarios. Similar to both Stratozone and SCIATRAN processors, only the radiance is corrected for the multiple scattering whereas the weighting functions are calculated in the single scattering approximation.

The retrieval approach is based on the solution of the modified minimization problem rather than that given by Eq. (5). First, assuming the initial noise covariance matrix, $\mathbf{S}_{\varepsilon}$, to be a symmetric and positive definite, the prewhitening technique (Rodgers, 2000) is applied to obtain the "normalized" data model with identity noise covariance matrix, $\mathbf{S}_{\varepsilon}=\mathbf{I}$. Further, assuming the a priori covariance matrix to be of the form $\mathbf{S}_{a}=\sigma_{a}^{2} \hat{\mathbf{S}}_{a}$, where $\sigma_{a}$ is the a priori standard deviation of the retrieved parameter, the stochastic regularization matrix $\mathbf{L}$ can be introduced by the Choleski factorization $\hat{\mathbf{S}}_{a}^{-1}=\mathbf{L}^{T} \mathbf{L}$. 

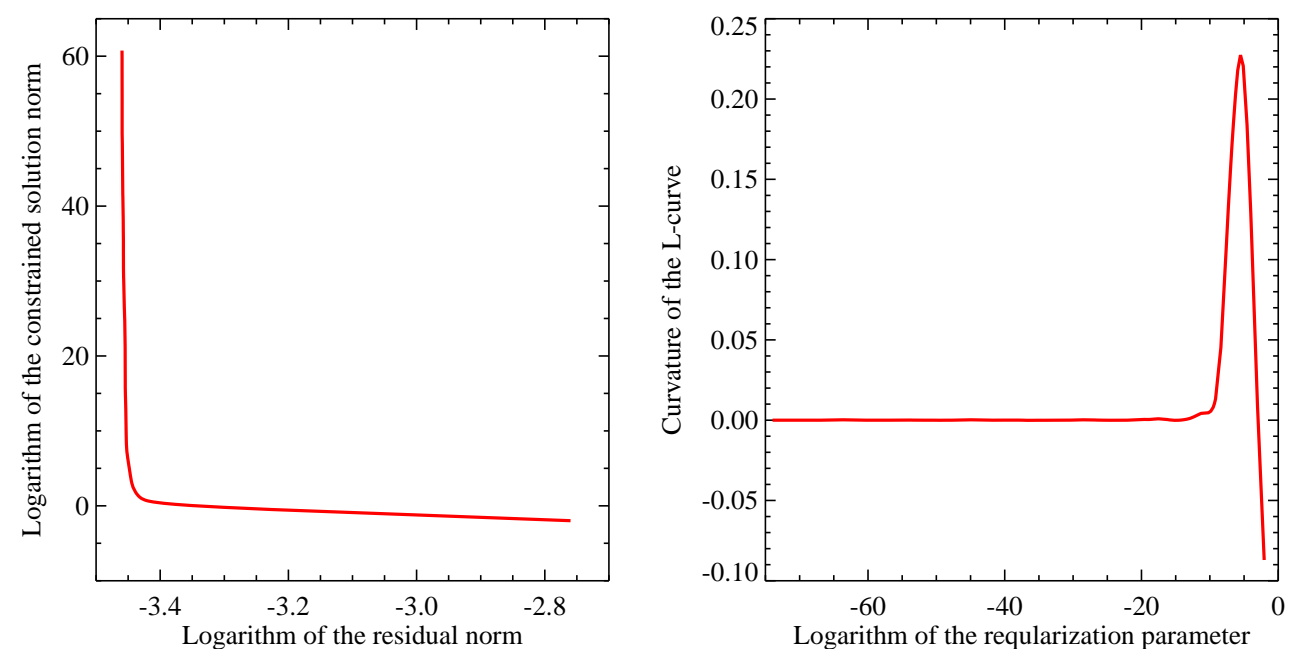

Fig. 1. Illustration of the L-curve method. Left panel: logarithm of the constrained solution norm versus the logarithm of the residual norm. Right panel: curvature of the L-curve as a function of the logarithm of the regularization parameter.

As a result, the minimization problem as given by Eq. (5) can be rewritten in the following form:

$$
\begin{aligned}
\mathcal{F}(\boldsymbol{x})=\left\|\mathbf{F}\left(\boldsymbol{x}_{\mathrm{a}}\right)+\mathbf{K}\left(\boldsymbol{x}-\boldsymbol{x}_{\mathrm{a}}\right)-\boldsymbol{y}_{\varepsilon}\right\|^{2}+ & \\
\lambda_{\mathrm{a}}^{2} & \left\|\mathbf{L}\left(\boldsymbol{x}-\boldsymbol{x}_{\mathrm{a}}\right)\right\|^{2},
\end{aligned}
$$

where $\lambda_{\mathrm{a}}=1 / \sigma_{\mathrm{a}}$ is the stochastic regularization parameter.

Unlike the Stratozone and SCIATRAN processors where a priori variances of the retrieved parameters are fixed during the retrieval, the DLR retrieval algorithm solves the minimization problem as given by Eq. (24) for a sequence of regularization parameters $\lambda_{a}$ looking for an optimal value. The optimal value of the retrieval parameter is selected by means of the L-curve method as illustrated by Fig. 1. The left panel shows the pairs of the logarithm of the constrained solution norm, $\left\|\mathbf{L}\left(\boldsymbol{x}-\boldsymbol{x}_{\mathrm{a}}\right)\right\|^{2}$, and the logarithm of the residual norm, $\left\|\mathbf{F}\left(\boldsymbol{x}_{a}\right)+\mathbf{K}\left(\boldsymbol{x}-\boldsymbol{x}_{\mathrm{a}}\right)-\boldsymbol{y}_{\varepsilon}\right\|^{2}$, obtained for different values of the regularization parameter $\lambda_{a}$. This plot is commonly referenced as the L-curve plot. The value of $\lambda_{a}$ corresponding to the maximum curvature of the L-curve is considered to be the optimal regularization parameter. The right panel of Fig. 1 shows the curvature of the L-curve presented in the left panel as a function of the logarithm of the regularization parameter, $\lambda_{a}$.

Having obtained the optimal value for the regularization parameter, $\lambda_{\text {opt }}$, the solution of the linearized inverse problem is written as:

$$
\boldsymbol{x}=\boldsymbol{x}_{\mathrm{a}}+\left(\mathbf{K}^{T} \mathbf{K}+\lambda_{\mathrm{opt}}^{2} \mathbf{L}^{T} \mathbf{L}\right)^{-1} \mathbf{K}^{T}\left(\boldsymbol{y}_{\varepsilon}-\mathbf{F}\left(\boldsymbol{x}_{\mathrm{a}}\right)\right)
$$

The non-linearity of the inverse problem is accounted for employing the Gauss-Newton iterative approach with a decreasing sequence of regularization parameters. In the framework of this approach, the optimal value of the regularization parameter estimated at each iterative step is not directly used to constrain the inverse problem. Instead, in a combination with the regularization parameter from the previous iterative step, it is used to obtain a new regularization parameter according to the following rule, e.g., at the $(i+1)$-th iterative step:

$\lambda_{i+1}=\left\{\begin{array}{cl}\xi \lambda_{\mathrm{opt}, i+1}+(1-\xi) \lambda_{i}, & \lambda_{\mathrm{opt}, i+1}<\lambda_{i} \\ \zeta \lambda_{i}, & \lambda_{\mathrm{opt}, i+1} \geq \lambda_{i}\end{array}\right.$.

Here, $\xi$ and $\zeta$ are the input parameters $(\xi, \zeta<1)$ defining how much the new regularization parameter deviates from its value at the previous iterative step, $\lambda_{i}$, whereas $\lambda_{\text {opt }, i+1}$ is the optimal regularization parameter chosen accordingly to the L-curve method at the current iterative step. Thus, the solution of the non-linear retrieval problem at the $(i+1)$-th iterative step is given by

$$
\begin{aligned}
\boldsymbol{x}_{\mathrm{i}+1}=\boldsymbol{x}_{\mathrm{a}}+ & \left(\mathbf{K}_{\mathrm{i}}^{T} \mathbf{K}_{\mathrm{i}}+\lambda_{\mathrm{i}}^{2} \mathbf{L}^{T} \mathbf{L}\right)^{-1} \times \\
& \mathbf{K}_{\mathrm{i}}^{T}\left(\boldsymbol{y}_{\varepsilon}-\mathbf{F}\left(\boldsymbol{x}_{\dot{1}}\right)+\mathbf{K}_{\mathrm{i}}\left(\boldsymbol{x}_{\mathrm{i}}-\boldsymbol{x}_{\mathrm{a}}\right)\right),
\end{aligned}
$$

The above discussed strategy for choosing the regularization parameter represents an extension of the L-curve method to the non-linear problems relying on the idea that a weaker regularization is required if the solution approaches to the true atmospheric state. More details on the described regularization technique can be found in (Doicu et al., 2002). The Gauss-Newton iterative process is stopped if the non-linear residuals obtained at two subsequent iterative steps differ by less than $1 \%$. Typically $3-5$ iterations are required to achieve the convergence. 
Table 1. Comparison of retrieval processors.

\begin{tabular}{|c|c|c|c|}
\hline & Stratozone & DLR processor & SCIATRAN \\
\hline Radiative transfer model & $\begin{array}{l}\text { SCIARAYS: double scatter- } \\
\text { ing, surface reflection }\end{array}$ & $\begin{array}{l}\text { LIDORT single scattering, } \\
\text { lookup tables for multiple } \\
\text { scattering (SCIATRAN) }\end{array}$ & $\begin{array}{l}\text { SCIATRAN: approximative } \\
\text { multiple scattering }\end{array}$ \\
\hline Spectral range & 525,600 , and $675 \mathrm{~nm}$ & $520-580 \mathrm{~nm}$ & $520-580 \mathrm{~nm}$ \\
\hline \multirow[t]{2}{*}{ Reference spectrum } & \multicolumn{3}{|c|}{ Limb measurement at upper tangent height (reference tangent height): } \\
\hline & $49 \mathrm{~km}$ & $43 \mathrm{~km}$ & $43 \mathrm{~km}$ \\
\hline Tangent height range & $9-46 \mathrm{~km}$ & $14-40 \mathrm{~km}$ & $14-40 \mathrm{~km}$ \\
\hline Fit technique & Triplet & Global fit & Global fit \\
\hline Measurement vector & Chappuis vector & $\begin{array}{l}\text { Normalized differential } \\
\text { spectra }\end{array}$ & $\begin{array}{l}\text { Normalized differential } \\
\text { spectra }\end{array}$ \\
\hline Fitted species & $\mathrm{O}_{3}$ & $\mathrm{O}_{3}, \mathrm{NO}_{2}, \mathrm{O}_{4}$ & $\mathrm{O}_{3}, \mathrm{NO}_{2}, \mathrm{O}_{4}$ \\
\hline State vector & $\begin{array}{l}\text { Ozone concentrations at all } \\
\text { altitude levels }\end{array}$ & $\begin{array}{l}\text { Ozone partial columns in all } \\
\text { altitude layers and vertical } \\
\text { columns of } \mathrm{NO}_{2} \text { and } \mathrm{O}_{4}\end{array}$ & $\begin{array}{l}\text { Ozone concentrations at all } \\
\text { altitude levels and vertical } \\
\text { columns of } \mathrm{NO}_{2} \text { and } \mathrm{O}_{4}\end{array}$ \\
\hline Signal to noise ratio & 100 & 1000 & 1000 \\
\hline A priori uncertainty & $100 \%$ & $\begin{array}{l}100 \% \text { for ozone, } \\
20 \% \text { for other species }\end{array}$ & $\begin{array}{l}100 \% \text { for ozone, } \\
20 \% \text { for other species }\end{array}$ \\
\hline Correlation radius & $3.3 \mathrm{~km}$ & $3.3 \mathrm{~km}$ & $3.3 \mathrm{~km}$ \\
\hline Solution method & Optimal estimation & $\begin{array}{l}\text { Iteratively regularized } \\
\text { Gauss-Newton method }\end{array}$ & $\begin{array}{l}\text { Information operator } \\
\text { approach }\end{array}$ \\
\hline $\begin{array}{l}\text { Iterative method } \\
\text { Regularization parameter }\end{array}$ & $\begin{array}{l}\text { Gauss-Newton } \\
\text { constant }\end{array}$ & $\begin{array}{l}\text { Gauss-Newton } \\
\text { variable, optimal regulariza- } \\
\text { tion parameter by L-curve } \\
\text { criterion }\end{array}$ & $\begin{array}{l}\text { Levenberg-Marquardt } \\
\text { constant }\end{array}$ \\
\hline
\end{tabular}

\section{General settings}

An intercomparison of retrieval methods, implementation details, and initial settings of the above discussed retrieval processors is presented in Table 1.

As discussed in Sect. 3 the Stratozone algorithm exploits the differential spectral signal in the entire Chappuis absorption band using the limb radiances averaged over $2 \mathrm{~nm}$ spectral intervals centered around 525, 600, and $675 \mathrm{~nm}$. The limb radiances are normalized with respect to the limb measurement performed at about $49 \mathrm{~km}$ tangent height during the same limb sequence. Only limb measurements performed at tangent heights between 9 and $49 \mathrm{~km}$ are considered in the retrieval, i.e., only these measurements are used to form the state vector. Both multispectral methods, i.e., the SCIATRAN retrieval package of the University of Bremen and the retrieval processor of DLR, exploit the spectral information in 520 to $580 \mathrm{~nm}$ wavelength interval. To improve the retrieval quality, the vertical columns of $\mathrm{NO}_{2}$ and $\mathrm{O}_{4}$ are estimated in combination with ozone retrievals using the same spectral information. The differential spectra are obtained subtracting a cubic polynomial from both measured and simulated data. Unlike the Stratozone method, the limb measurement performed at about $43 \mathrm{~km}$ tangent height during the same limb sequence is used as the reference spectrum and the set of limb measurements considered by the retrieval al- gorithm is restricted to the tangent height range between 14 and $40 \mathrm{~km}$.

The upper and lower tangent heights limiting the limb measurements used to form the data vector as well as the reference tangent heights were selected based upon the analysis of the information content of the measurements as well as signal to noise ratios of limb spectra. Since the information content of the limb measurements in Chappuis absorption band at tangent heights below $14 \mathrm{~km}$ is quite low, these tangent heights were not considered in the SCIATRAN and DLR processors to avoid a destabilization of the retrieval by strong absorption bands of the water vapor and $\mathrm{O}_{4}$. As reference spectra, single measurements at the reference tangent height were used, since, due to a rapid decrease of the signal to noise ratio of SCIAMACHY limb spectra with increasing altitude, averaging of several spectra measured at upper tangent heights does not change substantially the signal to noise ratio of the resulting reference.

The forward models incorporated in the considered retrieval processors were initialized using the same climatological data base provided by C.A. McLinden (Personal communication) containing monthly averaged vertical distributions of pressure, temperature, ozone, and $\mathrm{NO}_{2}$ for 10 degree latitude bands. The vertical distribution of $\mathrm{O}_{4}$ was calculated using the corresponding vertical profile of the air density. Furthermore, temperature dependent absorption cross sections 
of $\mathrm{O}_{3}$ and $\mathrm{NO}_{2}$ measured by the SCIAMACHY PFM Satellite Spectrometer (Bogumil et al., 2003) as well as the $\mathrm{O}_{4}$ cross section from (Greenblatt et al., 1990) were used. However, the Stratozone retrieval processor accounts only for ozone absorption and, thus, does not use any $\mathrm{NO}_{2}$ and $\mathrm{O}_{4}$ information. All three radiative transfer models account for the finite vertical instantaneous field of view, whereas the horizontal extension of the field of view is ignored.

For compatibility reasons, all processors were initialized with a constant surface albedo of 0.3 and an aerosol-free background atmosphere, whereas geographical databases are used in the Stratozone retrieval processor for the surface albedo and aerosol loading to generate off-line products provided to external users. However, since the influence of these atmospheric parameters on the retrieved ozone profiles is rather small, this simplification is not expected to affect the intercomparison of different retrievals. All other initialization parameters used in this study for the Stratozone retrieval processor remain the same as in the standard initialization dataset. Since both DLR and SCIATRAN processors are not used to generate any off-line products so far, no standard initialization parameters exist for these algorithms. The influence of clouds was completely neglected in the comparison which is also the case when generating the off-line products with the current version of the Stratozone retrieval processor. Generally, the impact of clouds is not considered to be an important issue for the current study since it is not expected to cause additional deviations between the results of different retrieval processors. Furthermore, for typical SCIAMACHY limb retrievals the effect of clouds is quite small anyway.

The diagonal elements of the a priori covariance matrices were selected in accordance with $100 \%$ a priori uncertainty for ozone and $20 \%$ a priori uncertainty for other atmospheric species if considered. The off-diagonal elements were obtained assuming a correlation length of $3.3 \mathrm{~km}$. The measurement error covariance matrix was assumed to be diagonal with diagonal elements corresponding to a wavelength independent signal to noise ratio of 1000 for multispectral methods and 100 for the triplet method. The lower signal to noise ratio for the triplet method results from the overall degradation of the limb signal quality around $600 \mathrm{~nm}$ as well as larger systematic errors due to a usage of information from different spectral channels to form the data vector (both SCIATRAN and DLR retrievals use only the spectral information from channel 3, whereas the Stratozone processor uses both channels 3 and 4). However, this does not mean that the Stratozone retrievals are stronger constrained because the effective differential signal from the entire Chappuis absorption band, as exploited by the Stratozone processor, is much stronger as compared to that in the short wavelength wing of the band exploited by both SCIATRAN and DLR algorithms.

Both SCIATRAN and Stratozone processors utilize equidistant retrieval grids of $1 \mathrm{~km}$ spacing whereas the grid spacing of $3.5 \mathrm{~km}$ is used in the DLR algorithm. The altitude discretization grids of the forward models incorporated in the retrieval processors were the same as the corresponding retrieval grids.

\section{Sensitivity of limb measurements}

Before the results of different retrieval processors are discussed it is worth analyzing the overall sensitivity of ozone limb retrievals. This will allow us to select the altitude region where the influence of the retrieval parameters is not too high and, thus, the results of all three retrieval processors can be expected to agree. The common way to analyze the sensitivity of the retrieval methods, which employ the optimal estimation technique or the Tikhonov regularization with an a priori parameter choice, is to look at the averaging kernels. In this case, the averaging kernels in the relevant altitude region are distinctly peaked at corresponding altitudes and their values can be used to characterize the information content of the measurements. Furthermore, the width of the averaging kernels provide an estimation of the vertical resolution of the retrieval. However, the averaging kernel is a quantity which make sense only for the ordinary optimal estimation technique as introduced by Rodgers (2000) as well as for the Tikhonov regularization with a constant regularization parameter, i.e., for a priori parameter choice methods. Whereas, for example, in the iteratively regularized GaussNewton method as employed in the DLR retrieval processor, the decreasing sequence of regularization parameters yields the identity averaging kernel matrix. As pointed out by Doicu et al. (2007), in the information operator approach, employed by the SCIATRAN retrieval processor, the regular representation for the averaging kernels as introduced by Rodgers (2000) is not valid and should be rewritten using the truncated gain matrix. Furthermore, as the Levenberg-Marquardt method is used, the averaging kernels characterize each particular iterative step only and are not representative for the whole retrieval process any more. Thus, only the Stratozone retrieval processor can be characterized by the averaging kernels in the common way. This is the reason why the investigation of the sensitivity of ozone limb retrievals will be done below on the basis of averaging kernels resulting from the Stratozone retrieval processor only. Nevertheless, the results of this investigation are expected to be representative for all three retrieval processors due to the fact that they use the same kind of information, i.e., multispectral measurements of the scattered solar radiation in the Chappuis absorption band in limb viewing geometry at nearly the same set of tangent heights, and the employed retrieval approaches are basically similar.

Since the regularization term commonly incorporates information on the a priori profile, the sensitivity of the retrieval and, thus, the averaging kernels are also dependent on the a priori information. Therefore, the investigation below will be done for two different ozone profiles specific to the tropical and to the high latitude regions. Example profiles 


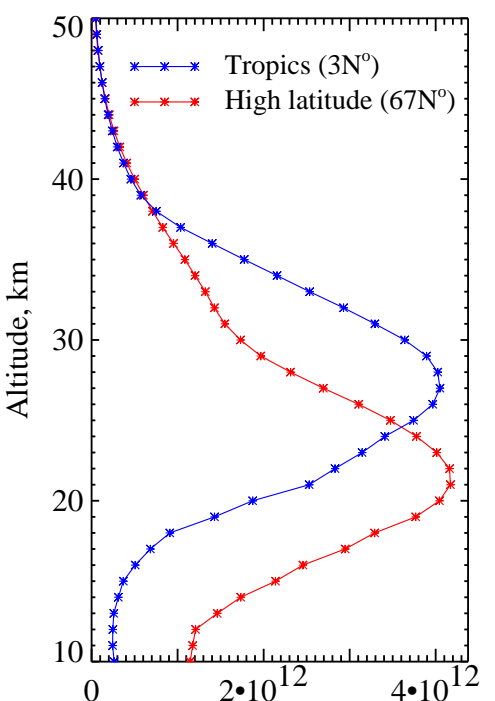

Ozone concentration, $\mathrm{molec} / \mathrm{cm}^{3}$

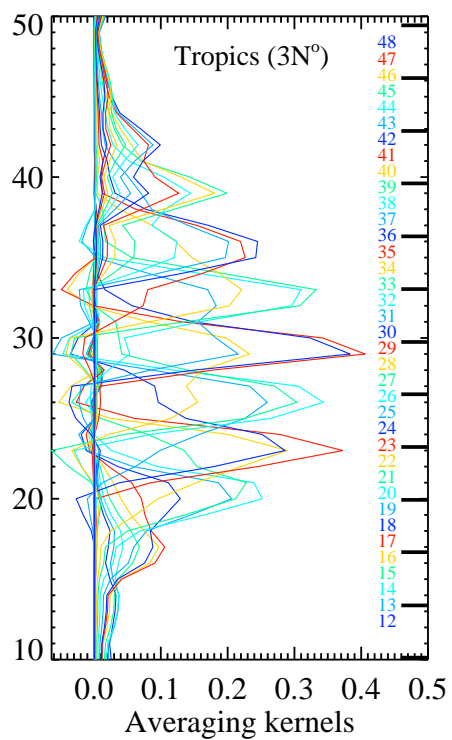

Averaging kernels

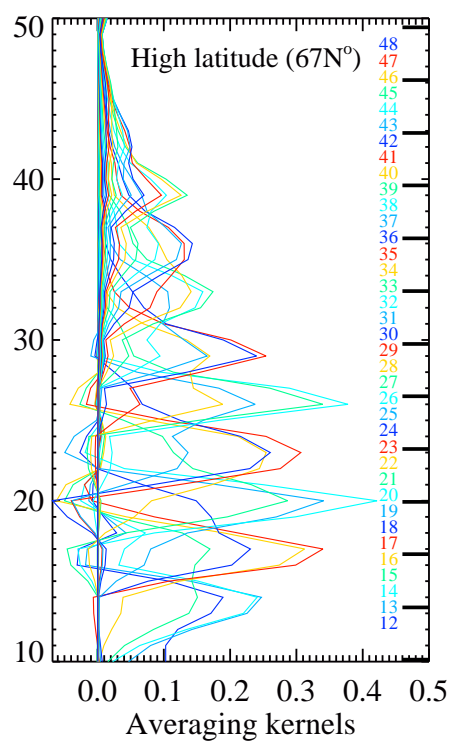

Fig. 2. Example ozone profiles for the tropical and the high latitude regions (left panel) as well as corresponding averaging kernels (middle panel for the tropical profile and right panel for the high latitude profile). The colored numbers on the right-hand side of the middle and right panels denote the altitudes which the averaging kernels were calculated for and the bold black bars indicate the tangent heights of the corresponding limb measurements.

for 20 September 2004, typical for the fall in these latitude regions are shown in the left panel of Fig. 2. As clearly seen, the high latitude profile exhibits much lower maximum altitude and much higher ozone number densities below $20 \mathrm{~km}$ as compared to the tropical profile. The corresponding averaging kernels are shown in the middle and the right panels of Fig. 2. The colored numbers on the right-hand side of the panels denote the altitudes which the averaging kernels were calculated for and the bold black bars indicate the tangent heights of the corresponding limb measurements. Since the measurements are performed with a tangent height sampling of about $3.3 \mathrm{~km}$ and the retrieval grid of $1 \mathrm{~km}$ spacing is used, the averaging kernels are expected to have the maximum values of 0.3 to 0.4 in the high sensitivity region.

Looking at the averaging kernels specific to the tropical region, as shown in the middle panel of Fig. 2, one clearly sees that the maximum sensitivity is reached between 23 and $33 \mathrm{~km}$ where the peak values of the averaging kernels are between 0.3 and 0.4 , whereas between 19 and $23 \mathrm{~km}$ as well as between 33 and $40 \mathrm{~km}$ they decrease to $0.2-0.25$ indicating a partial loss of the sensitivity. However, these peak values are still high enough to obtain good retrieval results, although an increased dependence on a priori information can be expected. Below $19 \mathrm{~km}$ and above $40 \mathrm{~km}$ the maximum values of the averaging kernels are below 0.1 indicating a low information content of the measurements and strong dependence of the results on the a priori information.

As shown in the right panel of Fig. 2, quite different results are obtained for a high latitude profile. Here the maximum sensitivity region moves to $16-27 \mathrm{~km}$ altitudes, whereas between 13 and $16 \mathrm{~km}$ as well as between 27 and $30 \mathrm{~km}$ the peak values of the averaging kernels are still about 0.25 indicating a fair information content of the measurements. Between 30 and $40 \mathrm{~km}$, where the peak values are between 0.1 and 0.2 , the measurements still have a certain sensitivity, however, an increased influence of the a priori information is expected. Above $40 \mathrm{~km}$, the averaging kernels drop below 0.05 and, thus, the retrieved values at these altitudes are expected to be dominated by a priori information.

Thus, based upon the discussion above, the target altitude region for the entire comparison can be selected as $\sim 18$ $35 \mathrm{~km}$, i.e., in this altitude region most of the measurements are considered to have a high information content and the results of all three retrieval processors are expected to agree.

\section{Comparison of the retrieval processors}

This section deals with a comparison of averaged retrieval results obtained using different algorithms. Since the DLR processor is still a prototype in a development phase and the SCIATRAN is a pure scientific algorithm, both processors were not applied to retrieve larger datasets so far and, thus, only limited datasets generated during the verification activities are available. For the comparison below, a data subset was selected where the results of all three retrieval processors are available assuring the averaging of the same sample distributions. 

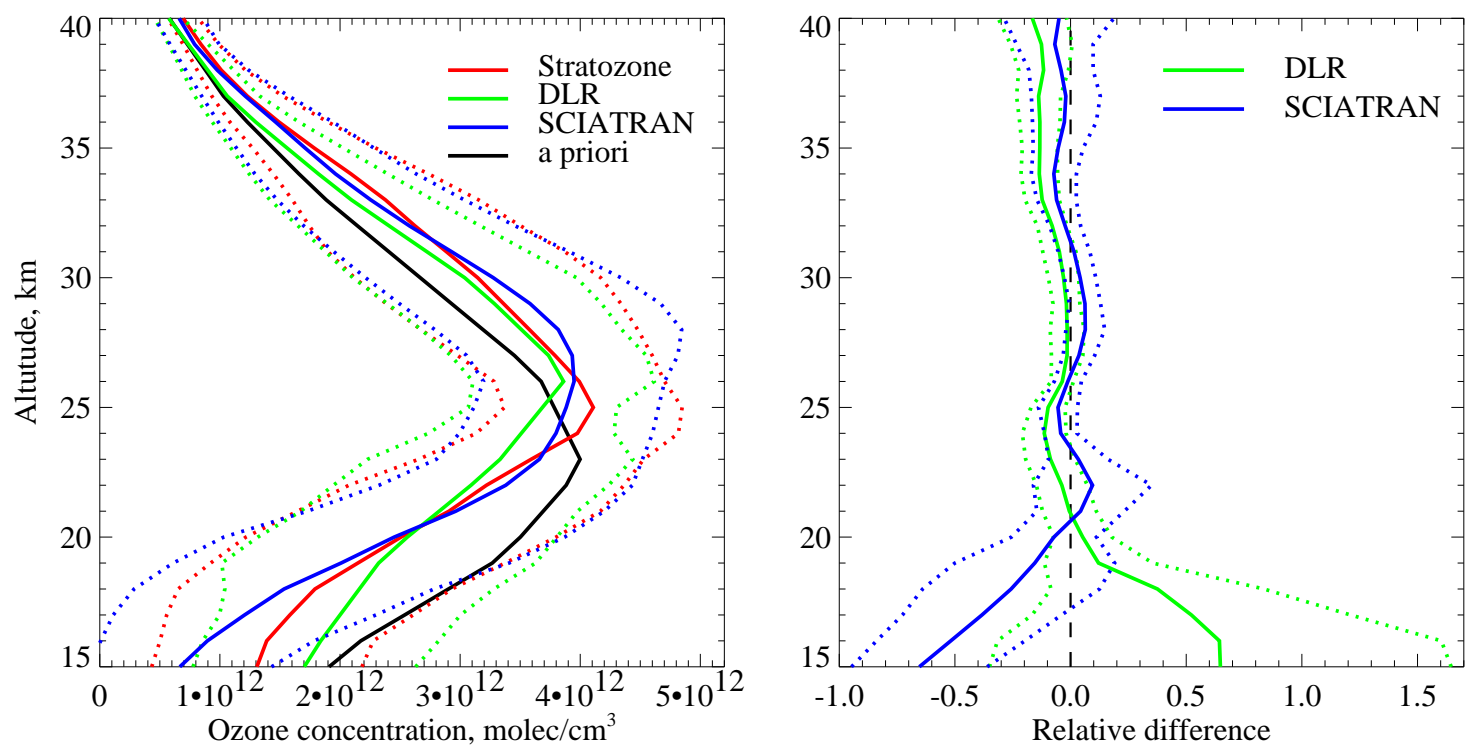

Fig. 3. Left panel: Mean ozone profiles retrieved by different algorithms (solid lines) and corresponding standard deviations (dotted lines) as well as mean a priori profile. The averaging was performed over all limb states included in the comparison. Right panel: The means of the relative differences of DLR and SCIATRAN results with respect to the Stratozone retrieval processor (solid lines) as well as the standard deviations of the relative differences (dotted lines).

The comparison was performed for 5 selected orbits incorporating 104 individual limb measurements. To investigate possible discrepancies between the results of considered retrieval processors in different latitude regions, three successive orbits in September 2004 with orbit numbers 13379, 13380, and 13381 were selected. Two additional orbits in January and March 2004 with orbit numbers 9816 and 10740, respectively, were selected to detect possible temporal variations in the closeness of agreement between the retrieval processors.

The overview of the comparison results is presented in Fig. 3 where the averaging over all considered limb states was performed. The left panel of Fig. 3 shows mean ozone profiles retrieved by different algorithms (color solid lines) and corresponding standard deviations (color dotted lines) as well as mean a priori profile (black solid line). The mean $\mathrm{O}_{3}$ profile resulting from the Stratozone processor routinely running at the University of Bremen is presented by the red line. The green line represents the results obtained from the prototype of the operational limb processor developed by DLR and the blue line depicts the mean profile obtained using the SCIATRAN retrieval package. The right panel of Fig. 3 shows the means of the relative differences of DLR and SCIATRAN results with respect to the Stratozone retrieval processor (solid lines) as well as the standard deviations of the relative differences (dotted lines). The color coding is the same as for the left panel.

As seen from the plot, the methods are in a good agreement between 19 and $40 \mathrm{~km}$, although a low bias of about
$10 \%$ is observed in the results of the DLR retrieval processor above $33 \mathrm{~km}$. Since the DLR results show the least deviation from the mean a priori profile, this low bias can be explained by a possible over-regularization of the DLR retrieval in this altitude range. However, according to the newest investigations of the DLR group this could also be an effect of insufficient resolution of the look-up tables for the multiple scattering correction with respect to the solar zenith angle. Below $19 \mathrm{~km}$ the agreement between results of different processors gets worse to about $60 \%$ at $15 \mathrm{~km}$ altitude, which is caused by a decreased sensitivity of the measurements and, thus, an increased influence of the retrieval implementation and initialization parameters. Around $15 \mathrm{~km}$ altitude, the DLR results seem to have a tendency to stick on the a priori information, whereas SCIATRAN profiles show the largest deviations from a priori. The latter is most probably the effect of the Levenberg-Marquardt type of the iterative scheme used in the SCIATRAN processor. This iterative method allows larger deviations from a priori constraining only the solution at each particular iterative step rather than the final solution but, on the other hand, it has a stronger sensitivity to systematic errors. Although the relative differences in the lower atmosphere are quite high, one should bear in the mind that the absolute differences are always below $8 \times 10^{11} \mathrm{molec} / \mathrm{cm}^{3}$ which is about $20 \%$ of the maximum values. Integrated between 15 and $40 \mathrm{~km}$, the SCIATRAN and DLR profiles agree within $0.3 \%$ whereas the corresponding partial column obtained from the Stratozone profiles is about 3\% larger. However, performing the integration only between 20 and $40 \mathrm{~km}$, 
an agreement of about $0.1 \%$ between the SCIATRAN and Stratozone processors is reached whereas the corresponding partial column obtained from the DLR retrievals is about $6 \%$ lower.

Despite an overall agreement, the vertical fineness of the averaged profiles is different which is caused by the usage of different retrieval grids in different methods $(1.0 \mathrm{~km}$ in both Stratozone and SCIATRAN, and $3.3 \mathrm{~km}$ in the DLR processor). This difference, however, is not expected to affect the vertical resolution of the retrieved profiles which is mainly determined by the instrument field of view (about $2.5 \mathrm{~km}$ at the tangent point) and by the vertical sampling of the SCIAMACHY limb measurements (about $3.3 \mathrm{~km}$ tangent height step). However, if the retrieval grid has finer layering than the tangent height sampling of the limb measurements, the algorithm is forced to perform some kind of interpolation in order to obtain the number densities between the measurement points. Thus, depending on the regularization method, the intermediate values of the number density can be estimated by the retrieval algorithm based on the overall vertical behavior of the profile. However, this approach can under some circumstances introduce fake vertical structures into the profiles. Additionally, the Information Operator approach employed in the SCIATRAN retrieval makes these profiles vertically smoother as compared to the results obtained by other methods, thus introducing larger smoothing error, see (Doicu et al., 2007) for details.

Looking at the mean relative differences with respect to the Stratozone processor in the right panel of Fig. 3, one can clearly see the same slightly oscillating vertical structure between 20 and $40 \mathrm{~km}$ for both SCIATRAN and DLR retrieval processors. This is a result of oscillations in the retrieved vertical profiles specific to the Stratozone processor, which were also seen by Brinksma et al. (2006) for previous versions of the algorithm. The reason for these oscillations is believed to be a higher sensitivity of the triplet method employed in the Stratozone processor to oscillations in the limb radiance profiles.

In the upper panel of Fig. 4 orbitally averaged ozone profiles retrieved by different algorithms in January, March, and September 2004 as well as corresponding a priori profiles are shown with the solid lines, whereas the dotted lines represent the corresponding standard deviations. In the same way, the lower panel of Fig. 4 presents the means of the relative differences of DLR and SCIATRAN results with respect to the Stratozone retrieval processor (solid lines) as well as the standard deviations of the relative differences (dotted lines). Each month is represented by one orbit and the averaging is performed over all limb measurements in the appropriate orbit. In all three seasons the profiles are in good agreement between 19 and $40 \mathrm{~km}$. Below $19 \mathrm{~km}$ the agreement becomes worse similar to the comparison in Fig. 3. Generally, the Stratozone and the DLR retrievals exhibit similar vertical behavior down to $19 \mathrm{~km}$ differing by up to $12 \%$ between 23 and $26 \mathrm{~km}$. In January and March the SCIATRAN retrievals are vertically smoother compared to the Stratozone results which can be explained by the additional smoothing specific to the retrieval method. However, in September both retrievals agree nearly perfectly above $18 \mathrm{~km}$. Similar to Fig. 3 the DLR results show the smallest deviations from a priori above $33 \mathrm{~km}$ and around $15 \mathrm{~km}$, whereas the strongest deviations occur for the SCIATRAN profiles below $18 \mathrm{~km}$. In September, both SCIATRAN and DLR retrievals show an additional negative bias of about $10 \%$ above $33 \mathrm{~km}$ which can be an indication of an overestimation of ozone concentrations by the Stratozone algorithm.

Figure 5 shows zonally averaged ozone profiles obtained from three orbits in September 2004 as well as corresponding a priori profiles with solid lines whereas the corresponding standard deviations are represented by the dotted lines. In the same way, Fig. 6 shows the means of the relative differences of DLR and SCIATRAN results with respect to the Stratozone retrieval processor (solid lines) as well as the standard deviations of the relative differences (dotted lines). The largest disagreement between the different retrievals is encountered in the tropical region $\left(20^{\circ} \mathrm{S}-20^{\circ} \mathrm{N}\right)$. Although the altitudes of the ozone maximum resulted from the different methods are in agreement, the Stratozone retrieval gives much larger altitude spread of the maximum concentration than found by two other methods. Furthermore, the ozone concentrations above $23 \mathrm{~km}$ retrieved by the DLR processor are systematically lower as compared to the results of Statozone and SCIATRAN which also differ by up to $10 \%$ from each other. These systematically lower ozone concentrations resulting from the DLR retrieval processor can not be explained by the differences in the retrieval algorithms. Rather, they are most probably caused by the differences in the forward models, namely, in the approaches to account for the multiple scattering contribution, which is strongest in the tropical region due to a high elevation of the Sun. On the contrary, the differences in the vertical structure of the Stratozone and SCIATRAN profiles are mostly explained by the different vertical interpolations performed by the retrievals. Indeed, taking into account that the measurement tangent heights are located at about 23.2, 26.5, and $29.7 \mathrm{~km}$, one see that at these altitudes the discrepancies are rather small, whereas fake bumps are introduced by the Stratozone and the SCIATRAN retrieval processors in $23.3-26.6 \mathrm{~km}$ and $26.6-$ $29.9 \mathrm{~km}$ altitude intervals, respectively. Unlike previously discussed retrievals, the ozone number densities resulting from the SCIATRAN processor are noticeable smaller than the Stratozone and DLR results already below $20 \mathrm{~km}$. This is most probably a result of a decreasing sensitivity to the lower layers because of high ozone content at high altitudes and low number densities below $20 \mathrm{~km}$. As a result, both Stratozone and DLR profiles tend to a priori values whereas the number densities resulting from the SCIATRAN retrieval are strongly affected by the values at higher altitudes.

In the midlatitude region of the Northern Hemisphere $\left(20^{\circ} \mathrm{N}-60^{\circ} \mathrm{N}\right)$ the SCIATRAN and Stratozone results agree 

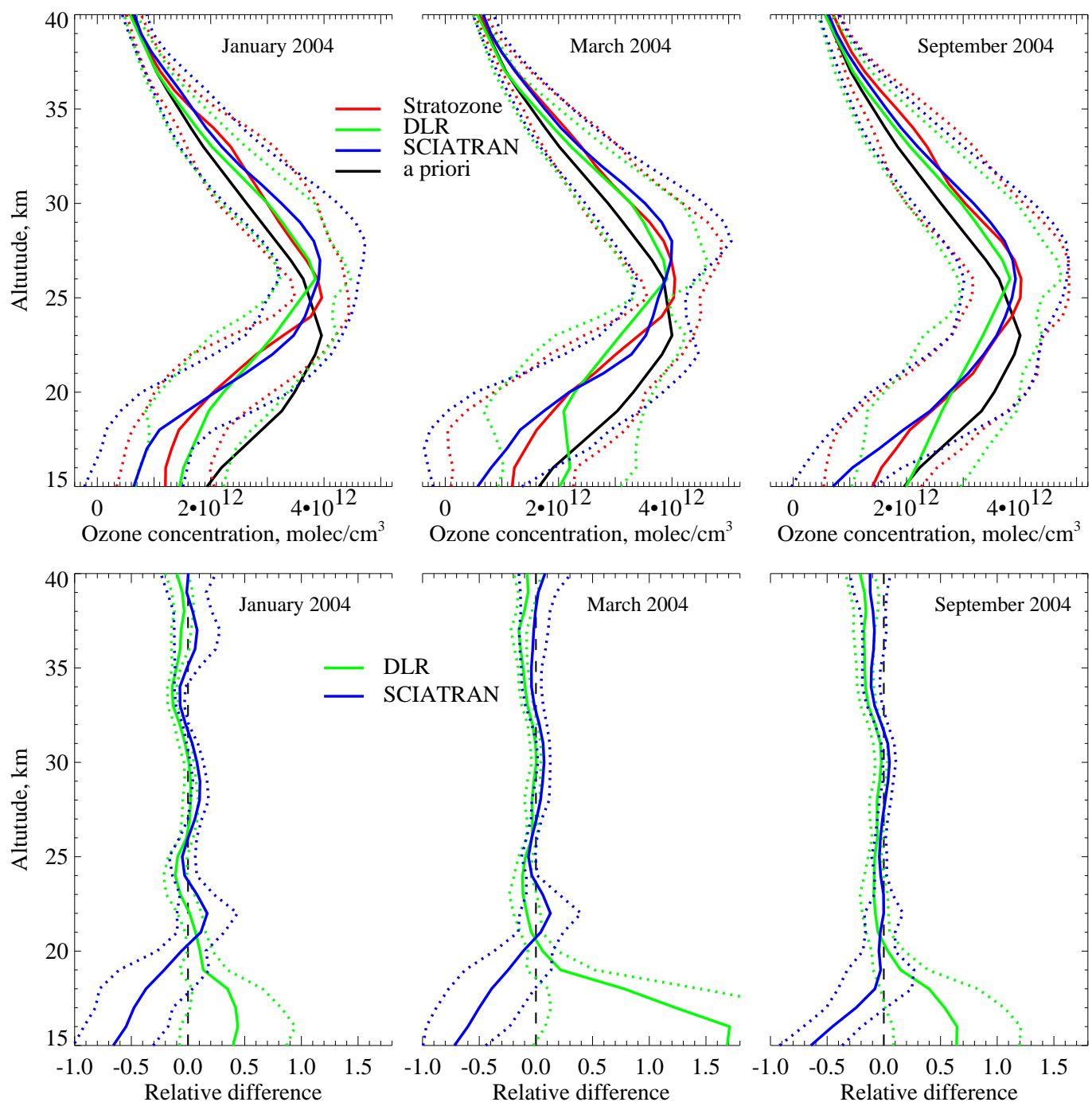

Fig. 4. Upper panel: Orbitally averaged ozone profiles retrieved by different algorithms in January, March, and September 2004 as well as corresponding a priori profiles shown with solid lines. The dotted lines represent the corresponding standard deviations. Lower panel: The means of the relative differences of DLR and SCIATRAN results with respect to the Stratozone retrieval processor (solid lines) as well as the standard deviations of the relative differences (dotted lines). The averaging was performed over 21 profiles in January, over 17 profiles in March, and over 22 profiles in September 2004.

within $5 \%$ between 19 and $35 \mathrm{~km}$, whereas the DLR results show a slight negative bias of about $5-10 \%$. Similar to previous comparisons, the disagreement increases below $19 \mathrm{~km}$ with DLR profiles tending to a priori and maximum deviation from a priori for SCIATRAN results. However, in the midlatitude region of the Southern Hemisphere $\left(20^{\circ} \mathrm{S}-60^{\circ} \mathrm{S}\right)$ no bias is observed between DLR and other retrievals between 19 and $33 \mathrm{~km}$. Here, the results of the Stratozone and DLR processors agree within 5\% with exception of the maximum region where the DLR processor is clearly missing the maximum concentration due to a coarser altitude discretization. The SCIATRAN and Stratozone results are generally in 5\% agreement between 17 and $40 \mathrm{~km}$, except for $27-30 \mathrm{~km}$ alti- tude range, where the SCIATRAN processor deviates up to $10 \%$ from the Stratozone due to different altitude interpolations by the retrieval algorithms. Unlike the Northern Hemisphere, the SCIATRAN and Stratozone results agree down to $17 \mathrm{~km}$ very well starting to deviate below, whereas the DLR profiles show the usual tendency to a priori already below $19 \mathrm{~km}$.

In the high latitude region of the Northern Hemisphere the Stratozone and SCIATRAN retrievals are in a very good agreement between 18 and $31 \mathrm{~km}$. Below $18 \mathrm{~km}$ the values resulted from the SCIATRAN retrieval are slightly lower compared to other methods, whereas above $31 \mathrm{~km}$ the Stratozone values are larger than DLR and SCIATRAN results. 

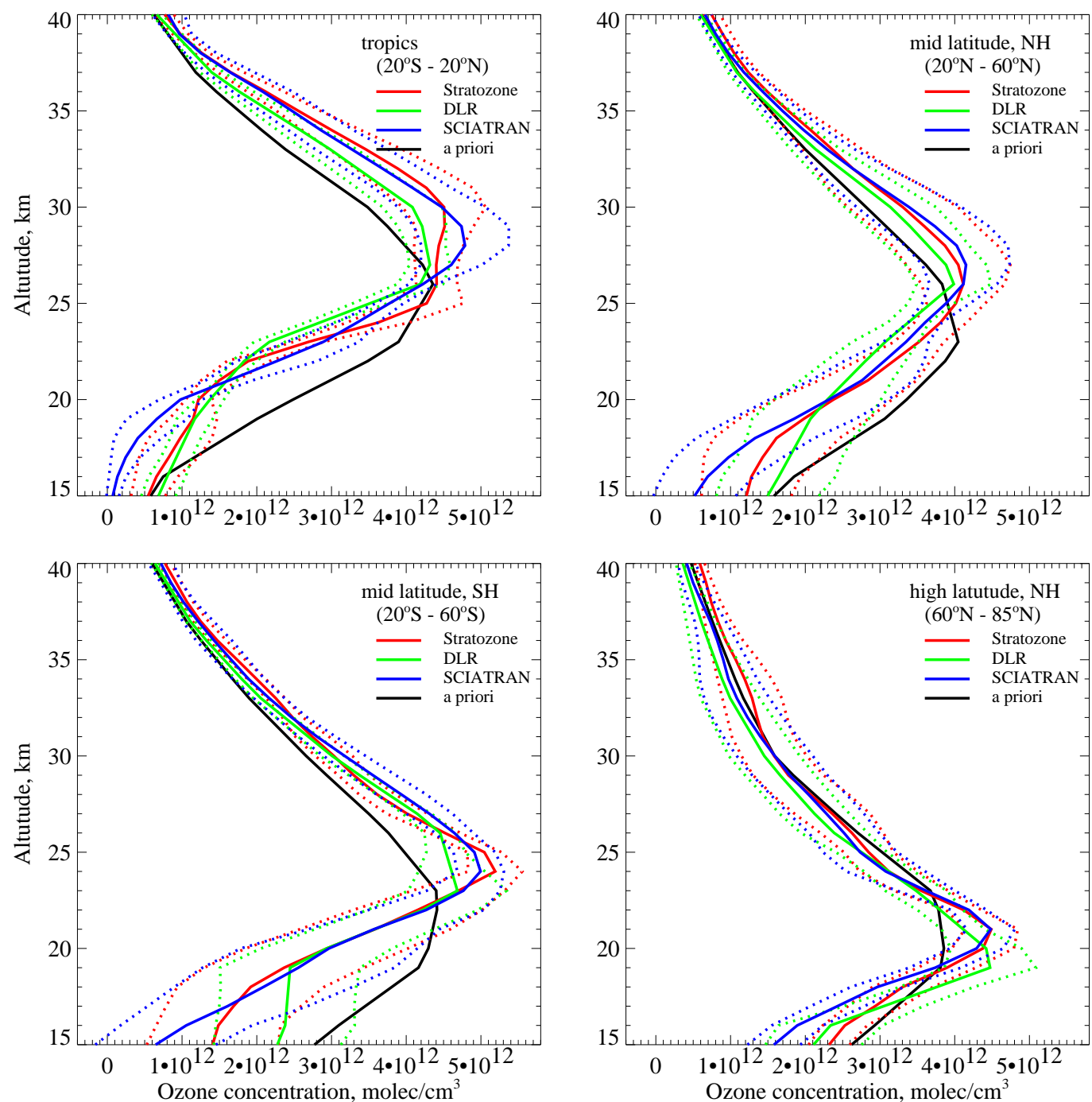

Fig. 5. Zonally averaged ozone profiles retrieved by different algorithms in September 2004 as well as corresponding a priori profiles shown with solid lines. The dotted lines represent the corresponding standard deviations. The averaging was performed over 13 profiles for the high latitude region of the Northern Hemisphere, over 17 profiles for the midlatitude region of the Northern Hemisphere, as well as over 16 profiles for both the midlatitude region of the Northern Hemisphere and the tropical region.

The DLR retrievals are in a very good agreement with SCIATRAN down to $24 \mathrm{~km}$. Below this altitude the DLR profile seems to be shifted downwards by 1 to $1.5 \mathrm{~km}$ remaining, nevertheless, within $10 \%$ agreement with Stratozone. Since, the measurements in the high latitude region are generally performed at larger solar zenith angles, the deviations in the vertical behavior of the ozone profiles resulting from the DLR retrieval processor are most probably due to the insufficient resolution of the look-up tables for the multiple scattering correction used in the forward model of this processor. Clearly, the dependence of the multiply scattered radiance on the solar zenith angle is stronger for the lower Sun causing, thus, larger deviations at high latitudes.

The high latitude region of the Southern Hemisphere was not considered due to a small number of limb measurements.

\section{Comparison to lidar measurements}

In this section selected non-averaged ozone profiles retrieved from SCIAMACHY limb observations using different retrieval processors are compared with collocated groundbased lidar measurements. The lidar ozone measurements considered here are obtained by the differential absorption lidar (DIAL) method, in which the atmosphere is sounded vertically by two laser beams at wavelengths with different ozone absorption cross-section (e.g., McDermid et al., 1990, 1991, 1995). Range resolved measurements are obtained with the use of pulsed lasers. The spectral range of the laser beams is chosen in the ultraviolet where the ozone absorption is most efficient. The ozone number density is computed from the differentiation of the lidar signals (Godin et al., 

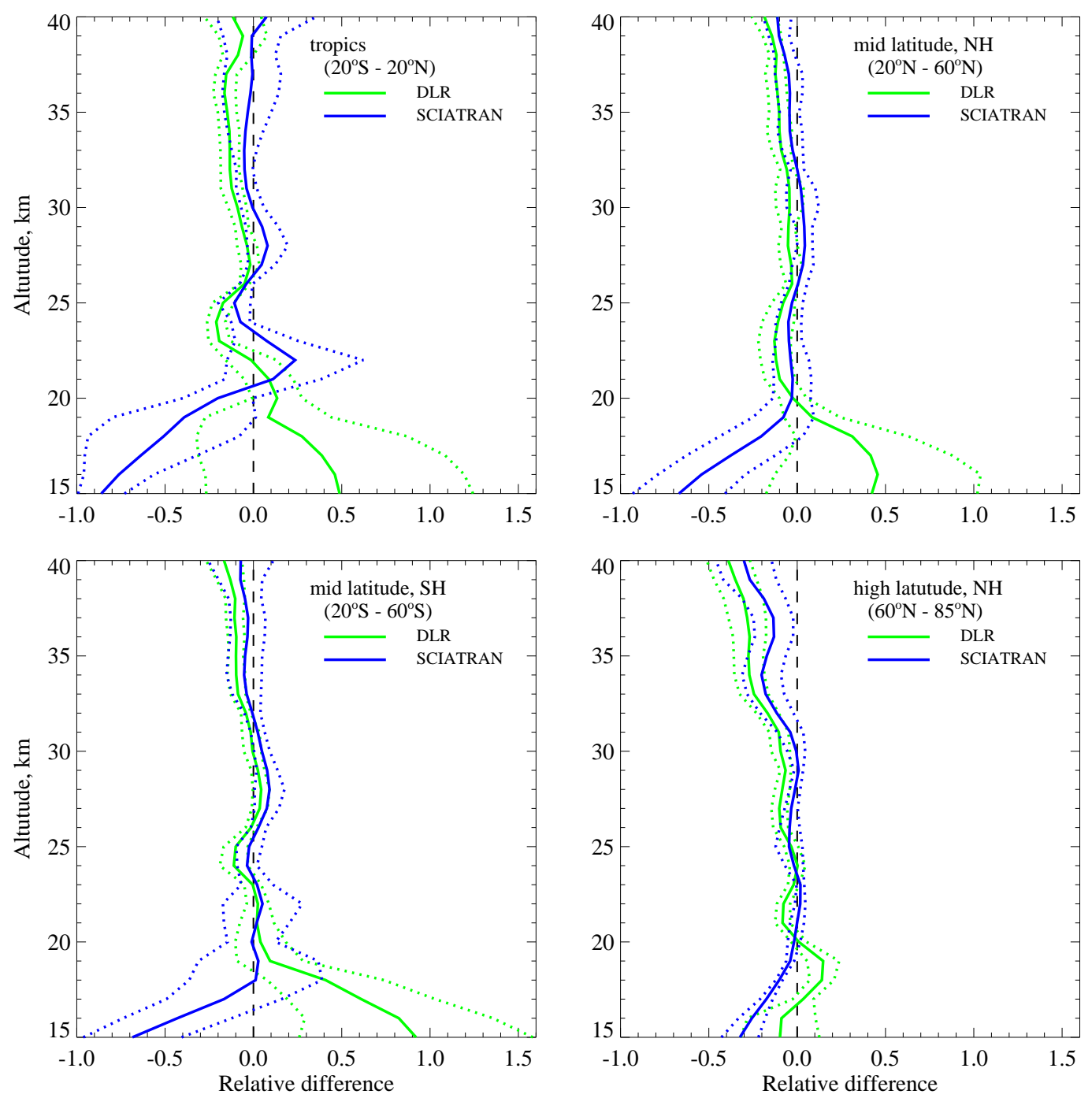

Fig. 6. The means of the relative differences of DLR and SCIATRAN results with respect to the Stratozone retrieval processor (solid lines) as well as the standard deviations of the relative differences (dotted lines) appropriate to zonally averaged profiles shown in Fig. 5.

1989, 1999; Godin-Beekmann et al., 2003). Due to the rapid decrease of the signal-to-noise ratio as a function of altitude, the retrieved ozone profile is smoothed with a low-pass filter characterized by a varying cutoff frequency as a function of altitude. The lidar measurements are performed during the night and last typically several hours. Owing to dynamic processes in the Earth's atmosphere, this results in a spatial resolution of about $100 \mathrm{~km}$, depending on the atmospheric conditions. The vertical resolution ranges from several hundred meters at lower altitudes to several kilometers above $40 \mathrm{~km}$. The total accuracy ranges from about a few percents below $20 \mathrm{~km}$ to more than $10 \%$ above $45 \mathrm{~km}$.

The results of all three SCIAMACHY retrieval processors were shifted vertically by a pointing correction value of about $-1.6 \mathrm{~km}$ as predicted by the TRUE algorithm (version 1.7). Exact pointing correction values for all considered colloca- tions are given below. The negative sign of the pointing correction value means that the corresponding profile is shifted downwards. A detailed description of the TRUE retrieval technique as well as the version history can be found in (von Savigny et al., 2005a, 2007). According to our previous investigations this post-processing correction, i.e., vertical shift of the retrieved number densities, results in nearly the same profiles as compared to the retrieval of the pointing corrected limb spectra.

The results of the comparison are shown in Fig. 7. Similar to the previous plots the SCIAMACHY retrievals are represented by colored lines. For clarity, only each third error bar is drawn for all retrievals. The corresponding lidar measurements are shown by the solid black lines with shaded areas representing the measurement uncertainties.

The left panel shows a comparison of ozone profiles 

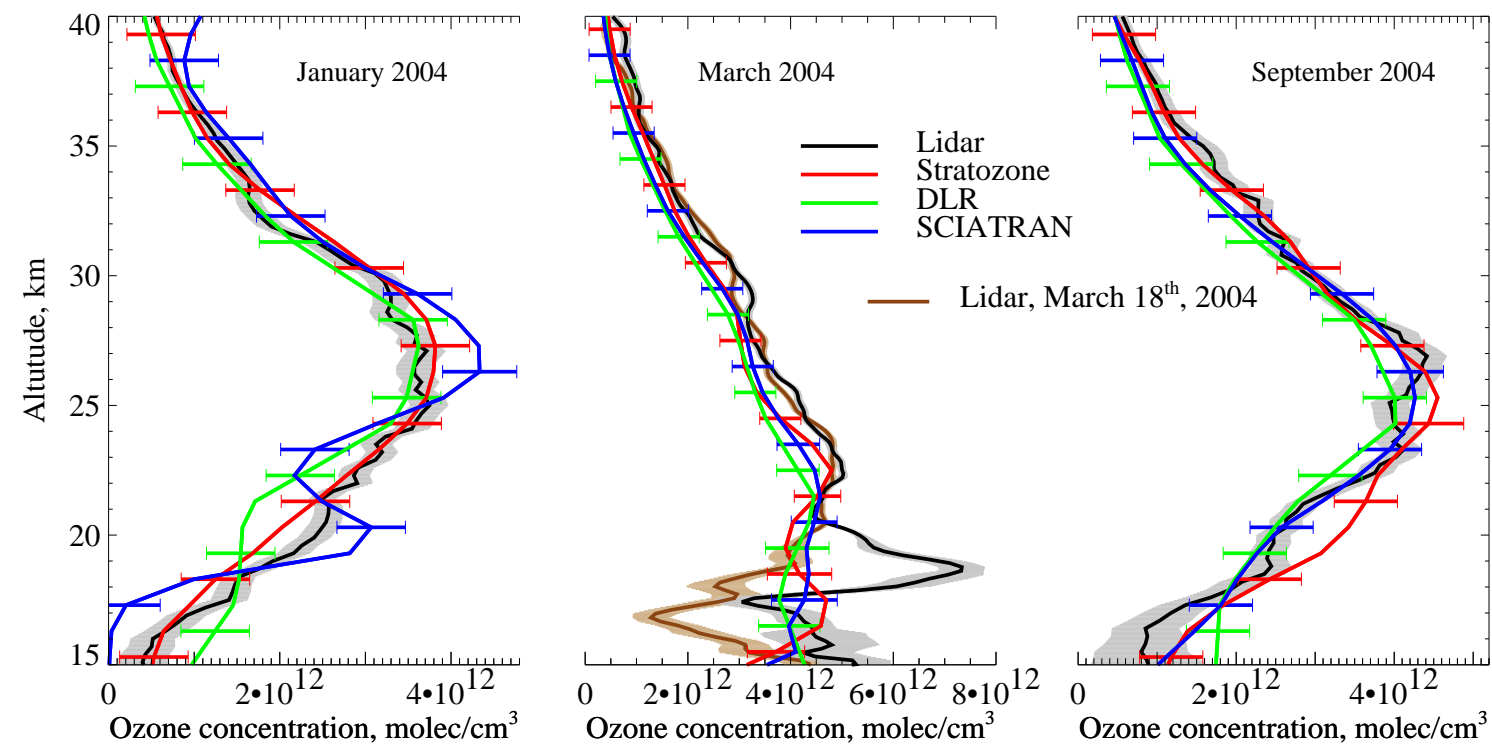

Fig. 7. Comparison to ground-based lidar measurements. Left panel: SCIAMACHY ozone profiles at average ground point coordinates $17.7^{\circ} \mathrm{N}, 155^{\circ} \mathrm{W}$ on 15 January 2004 at 20:20 UT compared to JPL-MLO lidar measurement at Mauna Loa Observatory (19.54 ${ }^{\circ}$, $155.58^{\circ} \mathrm{W}$ ) on 16 January 2004 at $05: 44$ UT. Middle panel: SCIAMACHY ozone profiles at average ground point coordinates $43^{\circ} \mathrm{N}, 14^{\circ} \mathrm{E}$ on 20 March 2004 at 09:28 UT compared to CNRS-OHP lidar measurement at Observatoire de Haute-Provence $\left(44^{\circ} \mathrm{N}, 5.7^{\circ} \mathrm{E}\right)$ on 19 March 2004 at 21:03 UT. To illustrate the high variability of the ozone vertical distribution in the lower stratosphere, the CNRS-OHP lidar profile measured on 18 March 2004 is also shown (brown line). Right panel: SCIAMACHY ozone profiles at average ground point coordinates $34.5^{\circ} \mathrm{N}, 119^{\circ} \mathrm{W}$ on 20 September 2004 at 18:10 UT compared to JPL-TMF lidar measurement at Table Mountain Facility (34.4 ${ }^{\circ} \mathrm{N}$, $117.7^{\circ} \mathrm{W}$ ) on 21 September 2004 at 06:14 UT.

retrieved from the SCIAMACHY limb measurement with average ground point coordinates $17.7^{\circ} \mathrm{N}, 155^{\circ} \mathrm{W}$ performed on 15 January 2004 at 20:20 UT with an ozone profile measured by the JPL-MLO lidar on 16 January 2004 at 05:44 UT over the Mauna Loa Observatory $\left(19.54^{\circ} \mathrm{N}, 155.58^{\circ} \mathrm{W}\right)$. All SCIAMACHY profiles were shifted by a pointing correction value of $-1.7 \mathrm{~km}$. Although the overall agreement is quite good none of the SCIAMACHY retrievals is in a perfect agreement with the lidar profile. Both Stratozone and SCIATRAN retrievals seem to be vertically shifted by about $1 \mathrm{~km}$ with respect to the lidar profile. The DLR retrieval is in a very good agreement with the lidar ozone profile down to $24 \mathrm{~km}$ resulting, however, in too low values below. Despite the apparent vertical shift, the Stratozone algorithm reproduces the overall shape of the ozone profile very well although it seems to miss the small second maximum at $20 \mathrm{~km}$. The SCIATRAN retrieval properly detects the position of both main and secondary maxima but the absolute values of the SCIATRAN ozone concentrations are differing by $15-20 \%$ from the lidar profile due to contaminating oscillations which are apparently caused by an under-regularization of the retrieved profile.

The middle panel shows a comparison of ozone profiles retrieved from the SCIAMACHY limb measurement with average ground point coordinates $43^{\circ} \mathrm{N}, 14^{\circ}$ E performed on 20
March 2004 at 09:28 UT with an ozone profile measured by the CNRS-OHP lidar on 19 March 2004 at 21:03 UT over the Observatoire de Haute-Provence (OHP, $\left.44^{\circ} \mathrm{N}, 5.7^{\circ} \mathrm{E}\right)$. All SCIAMACHY profiles were shifted by a pointing correction value of $-1.5 \mathrm{~km}$. As seen from the plot, all retrievals produce similar results matching the overall shape of the lidar ozone profile and fail to reproduce the sharp peak at $19 \mathrm{~km}$. Down to $21 \mathrm{~km}$, all retrievals agree within $10-15 \%$ with each other and with the lidar ozone profile. The lack of the ozone maximum at $19 \mathrm{~km}$ in all SCIAMACHY retrievals can either result from a coarse vertical sampling of the SCIAMACHY instrument ( $3.3 \mathrm{~km}$ tangent height step) in conjunction with an overall decrease of the retrieval sensitivity in the lower atmosphere or be caused by probing slightly different air masses. The latter is also in accordance with a high variability of the ozone vertical distribution in the lower stratosphere over OHP in the second half of March 2004. For example, the high ozone concentration at about $19 \mathrm{~km}$ measured by the CNRS-OHP lidar on 19 March 2004 is probably due to an ozone-rich polar vortex filament moving over OHP at this time. To illustrate this high temporal variability, the ozone profile measured by the CNRS-OHP lidar on 18 March 2004, i.e., one day before, is also shown in middle panel of Fig. 7 (brown line).

The right panel shows a comparison of ozone profiles 
retrieved from the SCIAMACHY limb measurement with average ground point coordinates $34.5^{\circ} \mathrm{N}, 119^{\circ} \mathrm{W}$ performed on 20 September 2004 at 18:10 UT with an ozone profile measured by the JPL-TMF lidar on 21 September 2004 at 06:14 UT over the Table Mountain Facility $\left(34.4^{\circ} \mathrm{N}\right.$, $117.7^{\circ} \mathrm{W}$ ). All SCIAMACHY profiles were shifted by a pointing correction value of $-1.7 \mathrm{~km}$. Similar to the previous plots, the shape of the ozone profiles retrieved from SCIAMACHY measurements agrees well with the shape of the lidar profile, although all SCIAMACHY retrievals exhibit less vertical structure compared to the lidar measurement. Obviously, this is caused by a partial loss of the information due to a coarse vertical sampling of the SCIAMACHY instrument. Down to $23 \mathrm{~km}$ all SCIAMACHY retrievals agree within $10-15 \%$ with each other and with the lidar ozone profile. However, below $23 \mathrm{~km}$ the agreement becomes worse due to a secondary maximum in the ozone profile resulting from the Stratozone retrieval.

\section{Conclusions}

Three different retrieval algorithms developed to gain vertical distributions of ozone from SCIAMACHY limb measurements are discussed. Two of them are the scientific algorithms developed at the University of Bremen and the third one is the prototype of the operational retrieval processor developed at the German Aerospace Center (DLR) in Oberpfaffenhofen on behalf of the European Space Agency. The results of different retrievals were compared with each other as well as with independent ground-based lidar measurements.

The intercomparison shows that between 19 and $33 \mathrm{~km}$ all retrieval methods are mostly within 5\% agreement. However, discrepancies up to $10 \%$ can occur at altitude layers located between measurement sampling heights due to different vertical interpolations specific to different retrieval approaches. In particular, due to a coarser retrieval grid used in the DLR retrieval processor, this algorithm can under some circumstances miss values in the ozone maximum, whereas both Stratozone and SCIATRAN retrievals can introduce fake vertical features between the measurement sampling altitudes. The ozone vertical profiles resulting from the Stratozone processor exhibit slight oscillations of about 5\% amplitude with respect to other results due to a higher sensitivity of the triplet method employed in this processor to the oscillations in radiance profiles. The results of the DLR retrieval processor often show a negative bias of about $5-10 \%$ as compared to other methods, especially above $33 \mathrm{~km}$. Below $19 \mathrm{~km}$, where the information content of the limb measurements decreases causing an increased influence of the retrieval constraints as well as systematic errors, the disagreement between different retrievals increases with decreasing altitude up to $50-80 \%$ at $15 \mathrm{~km}$. However, even for these high relative differences, the absolute values of the ozone concentrations differ by less than $8 \times 10^{11} \mathrm{molec} / \mathrm{cm}^{3}$ which is about $20 \%$ of the maximum values. Generally, in the lower atmosphere, the SCIATRAN results show the largest and the DLR results the smallest deviations from a priori. Being vertically integrated between 15 and $40 \mathrm{~km}$, the results of all retrieval processors agree within $3 \%$.

The comparisons of single ozone profiles retrieved from SCIAMACHY limb measurements using different retrieval methods with collocated ground-based lidar measurements show that the general shape of the ozone profiles and the retrieved amount of ozone is in good agreement although, due to a coarser vertical resolution, the fine vertical structure of the profiles can not be obtained from the satellite measurements. The quantitative agreement between SCIAMACHY and lidar profiles can be estimated as 10-20\% down to $22 \mathrm{~km}$ getting worse in the lower layers, which is in accordance with previously published validation results of precursor versions of the Stratozone retrieval processor (Segers et al., 2005; Brinksma et al., 2006).

Acknowledgements. This work was partially funded by the German Ministry of Education and Research (BMBF) through the German Aerospace Center (DLR) within the SADOS project (20EE0027). Some data shown here were calculated on German HLRN (HighPerformance Computer Center North) and NIC/JUMP (Jülich Multiprocessor System). Services and support are gratefully acknowledged. Lidar data were obtained as part of the regular measurement program funded by NASA/JPL and CNRS/SA in the frame of the Network for the Detection of Atmospheric Composition Changes (NDACC) and submitted by RIVM as part of the EQUAL project funded by ESA.

Edited by: W. Ward

\section{References}

Bogumil, K., Orphal, J., Homann, T., Voigt, S., Spietz, P., Fleischmann, O. C., Vogel, A., Hartmann, M., Bovensmann, H., Frerik, J., and Burrows, J. P.: Measurements of molecular absorption spectra with the SCIAMACHY pre-flight model: instrument characterization and reference data for atmospheric remotesensing in the 230-2380 nm region, J. Photochem. Photobiol. A., 157, 167-184, doi:10.1016/S1010-6030(03)00062-5, 2003.

Bovensmann, H., Burrows, J. P., Buchwitz, M., Frerick, J., Noël, S., Rozanov, V. V., Chance, K. V., and Goede, A. P. H.: SCIAMACHY: Mission objectives and measurement modes, J. Atmos. Sci., 56, 127-149, 1999.

Brinksma, E. J., Bracher, A., Lolkema, D. E., Segers, A. J., Boyd, I. S., Bramstedt, K., Claude, H., Godin-Beekmann, S., Hansen, G., Kopp, G., Leblanc, T., McDermid, I. S., Meijer, Y. J., Nakane, H., Parrish, A., von Savigny, C., Stebel, K., Swart, D. P., Taha, G., and Piters, A. J.: Geophysical validation of SCIAMACHY limb ozone profiles, Atmos. Chem. Phys., 6, 197-209, 2006 , http://www.atmos-chem-phys.net/6/197/2006/.

Doicu, A., Schreier, F., and Hess, M.: Iteratively regularized GaussNewton method for atmospheric remote sensing, Comput. Phys. Commun., 148, 214-226, doi:10.1016/S0010-4655(02)00555-6, 2002. 
Doicu, A., Hilgers, S., von Bargen, A., Rozanov, A., Eichmann, K.-U., von Savigny, C., and Burrows, J.: Information operator approach and iterative regularization methods for atmospheric remote sensing, J. Quant. Spectrosc. Radiat. Transfer, 103, 340 350, doi:10.1016/j.jqsrt.2006.05.002, 2007.

Flittner, D. E., Bhartia, P. K., and Herman, B. M.: $\mathrm{O}_{3}$ profiles retrieved from limb scatter measurements: Theory, Geophys. Res. Lett., 27, 2601-2604, doi:10.1029/1999GL011343, 2000.

Godin, S., Mégie, G., and Pelon, J.: Systematic lidar measurements of the stratospheric ozone vertical distribution, Geophys. Res. Lett., 16, 547-550, 1989.

Godin, S., Carswell, A. I., Donovan, D. P., Claude, H., Steinbrecht, W., McDermid, I. S., McGee, T. J., Gross, M. R., Nakane, H., Swart, D. P. J., Bergwerff, H. B., Uchino, O., von der Gathen, P., and Neuber, R.: Ozone differential absorption lidar algorithm intercomparison, Appl. Opt., 38, 6225-6236, 1999.

Godin-Beekmann, S., Porteneuve, J., and Garnier, A.: Systematic DIAL ozone measurements at Observatoire de Haute-Provence, J. Environ. Monit., 5, 57-67, doi:10.1039/b205880d, 2003.

Greenblatt, G. D., Orlando, J. J., Burkholder, J. B., and Ravishankara, A. R.: Absorption measurements of oxygen between 330 and 1140 nm, J. Geophys. Res., 95, 18 577-18 582, 1990.

Hoogen, R., Rozanov, V. V., and Burrows, J. P.: Ozone profiles from GOME satellite data: Algorithm description and first validation, J. Geophys. Res., 104, 8263-8280, doi:10.1029/1998JD100093, 1999.

Kaiser, J. W. and Burrows, J. P.: Fast weighting functions for retrievals from limb scattering measurements, J. Quant. Spectrosc. Radiat. Transfer, 273-283, 2003.

Kozlov, V.: Design of experiments related to the inverse of mathematical physics (in Russian), in: Mathematical Theory of Experiment Design, edited by C. M. Ermakov, Nauka, Moscow, 216246, 1983.

McDermid, I. S., Godin, S. M., and Lindquist, L. O.: Ground-Based laser DIAL system for long-term measurements of stratospheric ozone, Appl. Opt., 29, 3603-3612, 1990.

McDermid, I. S., Haner, D. A., Kleiman, M. M., Walsh, T. D., and White, M. L.: Differential absorption lidar systems at JPLTMF for tropospheric and stratospheric ozone measurements, Opt. Eng., 30, 22-30, doi:10.1117/12.55768, 1991.

McDermid, I. S., Walsh, T. D., Deslis, A., and White, M. L.: Optical systems design for a stratospheric lidar, Appl. Opt., 34, 62016210, 1995.

McPeters, R. D., Janz, S. J., Hilsenrath, E., and Brown, T. L.: The retrieval of $\mathrm{O}_{3}$ profiles from limb scatter measurements: Results from the Shuttle Ozone Limb Sounding Experiment, Geophys. Res. Lett., 27, 2597-2600, doi:10.1029/1999GL011342, 2000.

Noël, S., Bovensmann, H., Burrows, J. P., Frerick, J., Chance, K. V., Goede, A. H. P., and Muller, C.: The SCIAMACHY Instrument on ENVISAT-1, in: Sensors, Systems, and NextGeneration Satellites II, Proc. SPIE, vol. 3498, 94-104, 1998.

Platt, U.: Differential optical absorption spectroscopy (DOAS), in: Air Monitoring by Spectroscopic Techniques, edited by Sigrist, M., 27-84, John Wiley, Hoboken, N.J., 1994.
Rodgers, C. D.: Inverse methods for atmospheric sounding: Theory and practice, World Scientific, 2000.

Rozanov, A.: Modeling of radiative transfer through a spherical planetary atmosphere: Application to atmospheric trace gases retrieval from occultation- and limb-measurements in UV-VisNIR, Logos Verlag Berlin, Germany, 2001.

Rozanov, A.: SCIATRAN: Radiative transfer model and retrieval software package, http://www.iup.physik.uni-bremen.de/ sciatran, 2004-2007.

Rozanov, A., Rozanov, V., and Burrows, J. P.: A numerical radiative transfer model for a spherical planetary atmosphere: combined differential-integral approach involving the Picard iterative approximation, J. Quant. Spectrosc. Radiat. Transfer, 69, 491-512, doi:10.1016/S0022-4073(00)00100-X, 2001.

Rozanov, A., Bovensmann, H., Bracher, A., Hrechanyy, S., Rozanov, V., Sinnhuber, M., Stroh, F., and Burrows, J.: $\mathrm{NO}_{2}$ and $\mathrm{BrO}$ vertical profile retrieval from SCIAMACHY limb measurements: Sensitivity studies, Adv. Space Res., 36, 846-854 doi:10.1016/j.asr.2005.03.013, 2005a.

Rozanov, A., Rozanov, V., Buchwitz, M., Kokhanovsky, A., and Burrows, J. P.: SCIATRAN 2.0 - A new radiative transfer model for geophysical applications in the $175-2400 \mathrm{~nm}$ spectral region, Adv. Space Res., 36, 1015-1019, doi:10.1016/j.asr.2005.03.012, $2005 b$.

Segers, A. J., von Savigny, C., Brinksma, E. J., and Piters, A. J.: Validation of IFE-1.6 SCIAMACHY limb ozone profile, Atmos. Chem. Phys., 5, 3045-3052, 2005, http://www.atmos-chem-phys.net/5/3045/2005/.

von Savigny, C., Haley, C. S., Sioris, C. E., McDade, I. C., Llewellyn, E. J., Degenstein, D., Evans, W. F. J., Gattinger, R. L., Griffioen, E., Lloyd, N. D., McConnell, J. C., McLinden, C. A., Murtagh, D. P., Solheim, B., and Strong, K.: Stratospheric ozone profiles retrieved from limb scattered sunlight radiance spectra measured by the OSIRIS instrument on the Odin satellite, Geophys. Res. Lett., 30, 1755, doi:10.1029/2002GL01640, 2003.

von Savigny, C., Kaiser, J. W., Bovensmann, H., Burrows, J. P., McDermid, I. S., and Leblanc, T.: Spatial and temporal characterization of SCIAMACHY limb pointing errors during the first three years of the mission, Atmos. Chem. Phys., 5, 2593-2602, $2005 a$.

von Savigny, C., Rozanov, A., Bovensmann, H., Eichmann, K.-U., Noël, S., Rozanov, V. V., Sinnhuber, B.-M., Weber, M., Burrows, J. P., and Kaiser, J. W.: The ozone hole break-up in September 2002 as seen by SCIAMACHY on ENVISAT, J. Atm. Sci., 62, 721-734, doi:10.1175/JAS-3328.1, 2005b.

von Savigny, C., Rozanov, A., Bovensmann, H., Noël, S., Gottwald, M., Slijkhuis, S., Burrows, J. P.: Studying Envisat attitude with SCIAMACHY limb-scatter measurements, in: Proceedings of the Envisat Symposium 2007, ESA Special Publication SP-636, 2007.

Spurr, R. J. D., Kurosu, T. P., and Chance, K. V.: A linearized discrete ordinate radiative transfer model for atmospheric remote sensing retrieval, J. Quant. Spectrosc. Radiat. Transfer, 68, 689735, 2001. 